\title{
A vulnerabilidade social dos municípios do litoral do Paraná: construção do Índice de Vulnerabilidade Social (IVS) com base nos dados dos setores censitários IBGE 2010
}

\author{
Social vulnerability in the Paraná coastal municipalities: the construction of the Social \\ Vulnerability Index (IVS) based on data from census tracts IBGE 2010
}

Natália Tavares de Azevedo ${ }^{1}$

\section{Resumo}

Neste artigo apresenta-se o processo de construção do Índice de Vulnerabilidade Social aplicado aos municípios do litoral do Paraná, bem como a análise de alguns resultados. Adotou-se uma perspectiva histórico-crítica, considerando os processos de diferenciação socioespacial como homologamente relacionados aos processos de acumulação, diferenciação e reprodução social nas sociedades capitalistas. Assim, a construção da métrica da vulnerabilidade social - a condição de indefesa dos indivíduos e domicílios frente a mudanças e riscos - é entendida como uma etapa no processo de compreensão da produção da vulnerabilidade social, que se expressa espacialmente como formas de diferenciação e segregação e que deve ser interpretada a partir dos processos históricos concretos. O IVS foi construído reproduzindo parcialmente a metodologia do IPVS da Fundação Seade, do estado de São Paulo, levando em conta as dimensões socioeconômica e demográfica das desvantagens sociais. Os resultados apontam para uma abrangente situação de vulnerabilidade social nos setores rurais, com destaque para os municípios de Antonina e Guaraqueçaba, condição essa ligada ao declínio da importância das atividades agropecuárias historicamente observado no litoral do Paraná. As melhores situações nos setores rurais estão em Guaratuba e Morretes, municípios que apresentam uma produção agropecuária mais significativa economicamente. Já nos setores urbanos, aponta-se processos de segregação espacial ligados; em Paranaguá, as transformações na atividade portuária e ao declínio de sua importância na composição da economia no município. Nos municípios praiano-turísticos, a segregação espacial divide as áreas de moradia da população local, em grande parte migrantes de baixa renda, das áreas destinadas às segundas residências dos veranistas.

Palavras-chave: Vulnerabilidade social. Diferenciação socioespacial. Segregação socioespacial. Litoral do Paraná.

\begin{abstract}
This paper presents the construction process of the Social Vulnerability Index applied to the municipalities of the Paraná's coast, as well as the analysis of some results. It was adopted a historical critical perspective, considering the socio-spatial differentiation processes as homologously related to the accumulation processes, differentiation and social reproduction in capitalist societies. Thus, the construction of the metric of social vulnerability - the helpless condition of individuals and households facing changes and risks - is seen as a step in the process of understanding the production of social vulnerability, which is expressed spatially as forms of

\footnotetext{
${ }^{1}$ Doutora em Meio Ambiente e Desenvolvimento (UFPR). Professora do Programa de pós-graduação em Meio Ambiente e Desenvolvimento - PPGMADE/UFPR. Email: natytav@yahoo.com.br
} 
differentiation and segregation, that should be interpreted from the concrete historical processes. The IVS was built partially reproducing the IPVS methodology of SEADE, from the State of São Paulo, taking into account the socioeconomic and demographic dimensions of social disadvantages. The results point to a comprehensive situation of social vulnerability in rural areas, especially in the municipalities of Antonina and Guaraqueçaba, and this condition linked to the decline of the importance of agricultural activities historically observed on the coast of Paraná. The best situations in rural areas are in Guaratuba and Morretes, which are municipalities that have a more significant agricultural production economically. In urban areas, it is pointed out that the spatial segregation processes in Paranagua are linked to changes in port activity and the decline of its importance in the composition of the economy in the municipality. In beachy-tourist cities, spatial segregation divides the living areas of the local population, largely low-income migrants, and areas for second homes to vacationers.

Keywords: Social vulnerability; Social diferentiation; sociospacial segregation; Paraná coast

\section{Introdução}

O litoral paranaense já foi a área economicamente mais desenvolvida do estado, até o início do século XIX, com um primeiro momento focado na economia do ouro e posteriormente na produção agrícola, tendo como área mais dinâmica o litoral norte, como destacaram Pierri et al. (2006). O que não impedia, é claro, a existência de tensões internas que, como notam Zanoni et al. (2000), estiveram na base de um longo processo de diferenciação social. Dois séculos se passaram e o resultado da trajetória histórica com suas reconfigurações da divisão territorial do trabalho (HAESBAERT, 1999) foram de tal complexidade que a região foi caracterizada por Pierri, em 2003, como uma área que convive com o paradoxo da enorme riqueza natural, por um lado, e da pobreza social, por outro.

Atualmente, a microrregião de Paranaguá, que inclui os sete municípios, Antonina, Guaraqueçaba, Guaratuba, Matinhos, Morretes, Paranaguá e Pontal do Paraná, é a oitava do estado ao se considerar o Produto Interno Bruto (BDE/IPARDES, 2013). Porém, ao observar o PIB per capita municipal, Paranaguá é apenas o 22º entre os 399 municípios do Paraná, com Guaraqueçaba ficando na última colocação. Considerando que apenas crescimento econômico é uma abordagem limitante dos indicadores de desenvolvimento, ao se tomar como referência o IDH (2010) (que também possui seus limites), vê-se que a situação do litoral não é muito melhor sob essa perspectiva, sendo que o município mais bem colocado é Paranaguá, na $32^{a}$ posição no estado, com Guaraqueçaba na penúltima.

O espaço na zona costeira paranaense é produzido e apropriado hoje a partir de um conjunto de formas e/ou atividades, que condicionam a configuração desse cenário socioeconômico, que se 
constrói numa relação dialética entre os processos históricos concretos e as condições naturais (SANTOS, 2006). Pierri et al. (2006), analisando os usos mais propriamente costeiros, identificaram o portuário, a conservação, o turístico (especialmente o de segunda residência) e o pesqueiro. Acrescente-se a esses os usos urbanos e os agrários, ligados às atividades agropecuárias, ao se considerar os municípios do litoral em sua totalidade, que são bastante diversificados, com diferentes padrões técnicos de exploração e relações sociais na produção, como apontou Marchioro (2002a). No espaço rural, outros usos também se configuram ligados às novas e contemporâneas formas de produção dessas áreas, caracterizadas por uma pluriatividade que inclui o desenvolvimento de atividades como o lazer e o turismo, além dos já citados usos para a conservação da natureza, todos ligados à multifuncionalidade dessas áreas (BRANDENBURG et al., 2004). Ainda assim, o cenário mais geral da situação socioeconômica da população aponta para um quadro de vulnerabilidade social.

Como também apontam Pierri et al. (2006), a dinâmica econômica possui estreita relação com a dinâmica demográfica, condicionando seus processos e sua expressão socioespacial. No censo de 2010, registrou-se nos sete municípios do litoral uma população de 265.392, sendo que mais de metade da população, 140.469 habitantes, vive no município polo, Paranaguá, que tem na atividade portuária o eixo estruturador de sua economia. A população é dividida de forma bastante desigual no espaço, alcançando altas densidades demográficas nas áreas urbanas de Paranaguá e índices médios nos municípios praianos, enquanto as áreas rurais apresentam baixa densidade demográfica, além de ter apresentado declínio da população em termos absolutos nas últimas décadas.

Um dos fenômenos mais marcantes na produção do espaço na região nas últimas décadas foi a constituição de uma área de ocupação contínua nos e entre os municípios praiano-turísticos e Paranaguá, caracterizada, como apontam Deschamps e Kleinke (2000) e Esteves (2011), por uma ocupação de migrantes, em grande quantidade de baixa renda, em busca de melhores condições de vida em face do escasseamento de oportunidades na metrópole Curitiba e nas cidades do interior do estado. Embora esse fenômeno tenha perdido força na última década, o que pode ser constatado pela redução nas taxas anuais de crescimento demográfico, ele se mantém importante na composição territorial do litoral. Na década de 1990, a taxa anual de crescimento no estado do Paraná foi de 1,25\%, enquanto foi de 4,72\% em Guaratuba, 8,8\% em Matinhos, 11,05\% em Pontal do Paraná e 2,49\% no polo Paranaguá, o que demonstra a atratividade da região. Já na década de 2000, a taxa paranaense caiu para 0,89\% ao ano, enquanto os municípios litorâneos apresentaram 
1,65\%, 1,98\%, 3,86\% e 0,99\% (Guaratuba, Matinhos, Pontal do Paraná e Paranaguá, respectivamente).

Esses diferentes usos e formas de ocupação do território, ligados às dinâmicas econômicas e demográficas, mas também políticas e sociais, resultam em formas particulares de distribuição espacial da população. Esses processos contemporâneos de produção do espaço, tanto nas áreas urbanas e metrópoles - onde se expressam de forma mais contundente, produzindo um urbanismo de risco (ROLNIK, 1999) - quanto nas áreas rurais, especialmente em países e áreas marcadas pela forte desigualdade social, como é o caso do Brasil, resultam em uma forte diferenciação e/ou segregação socioespacial (CARLOS, 2007). Dinâmicas econômicas e processos decisórios concorrem para o processo de vulnerabilização, como aponta Acselrad (2015), de parte significativa da população, que por um lado, é alijada do acesso aos seus direitos econômicos e sociais em face da lógica capitalista de acumulação, e por outro, é relegada a ocupar espaços degradados, expostos a riscos ambientais e sem a infraestrutura necessária.

Em face desse cenário, o objetivo central deste artigo é apresentar o processo de construção e alguns resultados de um Índice de Vulnerabilidade Social (IVS) aplicados ao litoral do Paraná. Essa construção foi feita no âmbito do projeto de pesquisa de pós-doutorado desenvolvido pela autora, intitulado "Vulnerabilidade socioambiental na zona costeira do Paraná com foco na pesca: estado atual e processos determinantes". A proposta desta pesquisa é identificar as situações de vulnerabilidade socioambiental nos municípios que compõem a zona costeira paranaense, visando compreender as condições das comunidades pesqueiras do litoral paranaense nesse contexto. Porém, além de visibilizar a situação dos pescadores artesanais, considera-se fundamental compreender o processo de diferenciação e segregação socioespacial do litoral já existente, tendo em conta a perspectiva de um novo ciclo para o litoral, com a projetada expansão da atividade portuária (OLIVEIRA, 2013; GÓES, 2014), bem como diante dos projetos de desenvolvimento da aquicultura marinha (SILVA, 2015) que pode levar à potencialização desses processos e à ampliação de situações de injustiça ambiental (ACSELRAD et al., 2009).

Uma vez que se compreende, com base em Alves (2006), que a vulnerabilidade socioambiental é a sobreposição da vulnerabilidade social com os riscos ambientais, buscou-se criar uma ferramenta capaz de dar visibilidade à distribuição espacial da população segundo sua vulnerabilidade social, tendo em conta as dimensões socioeconômica e demográfica, sendo este o foco deste artigo.

Iniciou-se, portanto, com o procedimento de construção de um indicador de vulnerabilidade social, de forma a identificar a espacialização das áreas mais suscetíveis, ou seja, nas quais os 
indivíduos e comunidades possuem menos acesso à riqueza socialmente produzida e nas quais sofrem maiores privações em suas diferentes formas de manifestação na organização social. Buscou-se interpretar esses resultados por meio da triangulação com informações qualitativas e históricas sobre o processo de desenvolvimento do litoral.

\section{Bases teóricas e metodológicas para a construção do Índice de Vulnerabilidade Social}

\section{Aspectos teóricos sobre desigualdade, diferenciação e segregação socioespacial e vulnerabilidade social}

Como já se deixa antever na introdução, toma-se como perspectiva teórica neste trabalho abordagens que são tributárias do materialismo histórico-geográfico de David Harvey (2005) e Edward Soja (1993), além de Milton Santos (2006). Como coloca Soja (1993), a estrutura do espaço organizado não é separada, com leis autônomas de construção e transformação, mas também não é simplesmente uma expressão da estrutura de classes que emerge das relações sociais. Para o autor, ela é - a estrutura do espaço - um componente dialeticamente definido das relações de produção gerais, que são simultaneamente sociais e espaciais. Ainda de acordo com o autor, existe uma homologia espacial correspondente às relações de classe, bem como com as contingências do conflito de classe e da transformação estrutural. Essa homologia, segundo Soja (1993, p. 99), pode ser verificada:

[...] na divisão regionalizada do espaço organizado em centros dominantes e periferias subordinadas, em relações espaciais de produção socialmente criadas e polarizadas, captáveis com maior precisão no conceito de desenvolvimento geográfico desigual. Essa conceituação dos vínculos entre a diferenciação social e espacial não implica que as relações espaciais de produção ou a estrutura centroperiferia sejam separadas e independentes das relações sociais de produção, das relações de classe. Ao contrário, os dois conjuntos de relações estruturadas (o social e o espacial) são não apenas homólogos, no sentido de provirem das mesmas origens no modo de produção, como também dialeticamente inseparáveis.

Harvey (2005) e Soja (1993) construíram a noção de "desenvolvimento geograficamente desigual" como centro explicativo das diferenciações socioespaciais. No centro do processo constitutivo da diferenciação, iluminam a noção de "desigualdade", que esclarece a existência de uma sociedade de classes que diferencia os seus membros a partir do lugar que ocupam tanto na produção quanto na distribuição da riqueza gerada. Trata-se de considerar o papel da divisão espacial do trabalho como elemento articulador/diferenciador dos lugares. 
Esses processos têm, como nota Harvey (2004), um caráter multi/trans escalar, em especial ao se considerar a globalidade do sistema do capital atual, em face do regime de acumulação flexível e da financeirização. Segundo esse autor, em qualquer escala particular que se examine o mundo, revela-se de imediato uma série de efeitos e processos que produzem diferenças geográficas nos modos de vida, nos padrões de vida, nos usos dos recursos, nas relações com o ambiente e nas formas políticas e culturais.

A questão da escala é pertinente, uma vez que, como aponta Carlos (2007), a diferenciação se estabelece e se realiza a partir do lugar, entre escalas e em cada uma delas. Um conjunto complexo de mediações interescalares de âmbito político, econômico e social se estabelece, condicionando as expressões espaciais da desigualdade. Um aspecto relevante é apontado por Brandão (2012) - a necessidade de pensar, a partir dessas determinações gerais, cada situação concreta a partir de sua historicidade, ou seja, captar e apreender as manifestações concretas dos fenômenos inerentes à dimensão espacial do processo de desenvolvimento capitalista em cada situação específica - as frações do capital em disputa, o nível de acumulação, as formas de atuação do Estado, os conflitos e lutas etc.

Assim compreendido, pode-se depreender que mesmo em regiões periféricas, como o caso do litoral paranaense, a estrutura de classes da sociedade se expressa espacialmente, fazendo com que existam áreas ricas e pobres, vulneráveis e privilegiadas, que tem como sua última unidade o habitar, o domicílio e os indivíduos.

A partir dessa orientação geral, entende-se que a distribuição espacial da vulnerabilidade social deve ser compreendida no escopo do processo de produção e apropriação do espaço, do desenvolvimento espacial desigual, que se manifesta nas múltiplas escalas, e no âmbito local e regional, por meio de processos de diferenciação e segregação socioespacial. A construção de uma métrica de vulnerabilidade social, portanto, permite compreender (com seus limites), na escala regional, as formas de distribuição da riqueza socialmente produzida, ao mesmo tempo que ilumina - ainda que apenas parcialmente - os déficits do Estado, por meio de suas políticas, de garantir os direitos devidos a todos os cidadãos.

Assim, entende-se a vulnerabilidade social como uma condição de incapacidade de defesa dos indivíduos e famílias em um ambiente em mudança, como é apontado na literatura geral sobre o tema (KAZTMAN, 2002). Porém, dá-se ênfase à necessidade de compreensão dos processos de vulnerabilização. Essa é uma leitura particular no debate sobre vulnerabilidade, e aqui se pode recorrer à Acselrad (2013, 2015), que estabelece uma crítica à leitura individualizante e liberal da vulnerabilidade social, assentada nas noções de ativos e capitais, demandando uma compreensão 
processual da vulnerabilização. Dessa forma, entende-se que a métrica da vulnerabilidade social que aqui se constrói deve estar ligada a um entendimento mais abrangente, como o proposto, da produção da desigualdade social e espacial, bem como do papel do Estado em garantir o acesso a todos os cidadãos aos seus direitos. Há que se destacar, contudo, que no espaço de um artigo, há limites para o duplo movimento de uma identificação das situações de vulnerabilidade e sua leitura processual. Nesse sentido, os resultados aqui apresentados oferecem apenas uma primeira leitura da visão espacializada da vulnerabilidade social na região, com os limites inerentes.

\section{Aspectos da construção da métrica da vulnerabilidade social}

Ao se considerar a escala regional que se buscou atingir nesta pesquisa, uma série de condicionantes metodológicos se colocam para sua realização. A primeira delas diz respeito aos possíveis recortes intraescalares e as fontes de dados disponíveis para uma leitura que produza o menor nível escalar possível para compreender a distribuição espacial da riqueza/pobreza, tornando possível identificar onde estão os vulnerabilizados (e num segundo momento, quem são e por que o são).

Assim sendo, inicialmente, foi realizado um amplo levantamento bibliográfico sobre metodologias quantitativas de análise da vulnerabilidade social. Identificou-se uma série de metodologias, como o Índice de Vulnerabilidade Social da Amazônia (IVSAm) (SEPLAN, 2007), o Índice Paulista de Vulnerabilidade Social (IPVS) (SEADE, 2013), o Índice de Qualidade de Vida Urbana de Belo Horizonte (IQVUBH) (PMBH, 2008), Índice de Vulnerabilidade das Famílias, no Paraná (IPARDES; NAZARENO et al., 2012), entre muitos outros, apenas em âmbito nacional. Mais recentemente, em 2015, já após a conclusão da construção dos índices que se apresenta aqui, o Instituto de Pesquisa Econômica Aplicada (IPEA, 2015) lançou um índice para os municípios e em escala intraurbana para as regiões metropolitanas. Em âmbito internacional, destaca-se o trabalho de Susan Cutter (2011), geógrafa norte-americana que desenvolve metodologias para a análise de vulnerabilidade do lugar, utilizando também dados censitários e categorizando-os para compor um índice de vulnerabilidade social, que posteriormente é cruzado com dados de riscos ambientais para compor um mapa de vulnerabilidade do lugar.

As diferentes metodologias se baseiam em distintas fontes de dados para a composição dos índices: baseados em sistemas de dados municipais, como no caso do índice de Belo Horizonte, ou em dados do Cadastro Único do Ministério do Desenvolvimento Social (MDS), como no caso do índice do Paraná, ou ainda, baseado nos dados dos Censos Demográficos realizados pelo IBGE, como os índices produzidos pelo Ipea e pela Seade. As metodologias que utilizam os dados do 
Cadastro Único, apesar de terem um conjunto de dados mais específico para a análise da vulnerabilidade social, só estão disponíveis para pessoas aí incluídas, ou seja, aqueles que buscam as políticas socioassistenciais. Isso impede a espacialização adequada e a comparação de grupos com distintas características de vulnerabilidade. Os dados municipais, de forma geral, só são disponíveis em municípios maiores, com maior capacidade administrativa e ferramentas próprias de gestão, como é o caso de Belo Horizonte.

Para a espacialização mais aproximada na realidade do litoral do Paraná, portanto, os dados secundários disponíveis considerados mais adequados são aqueles produzidos pelo Censo Demográfico do IBGE, realizado a cada 10 anos. Os resultados do questionário aplicado ao universo são aqueles que permitem comparar a totalidade dos setores censitários. Apesar de ser um questionário mais curto e simplificado, abrange variáveis socioeconômicas e demográficas que possibilitam uma comparação e agrupamento entre eles. Os dados dos questionários da amostra não são apresentados por setores, e isso impede sua utilização para a categorização da totalidade dos setores censitários. Para metrópoles, é possível utilizar os dados da amostra para áreas de ponderação, que são recortes espaciais intraurbanos.

Após vários testes, optou-se por replicar, com pequenas adaptações, a metodologia utilizada pela Fundação Seade (SEADE, 2013), de São Paulo, na construção do Índice Paulista de Vulnerabilidade Social (IPVS). Trata-se de um índice que se apoia nas elaborações de pesquisadores ligados à Cepal, como Kaztman (1999, 2000), em relação aos ativos sociais e sua distribuição. $\mathrm{O}$ autor entende a vulnerabilidade como um estado dos domicílios que varia em relação inversa a sua capacidade de controlar as forças que modelam seu destino, ou para se opor aos seus efeitos sobre seu bem-estar. Entende-a como uma defasagem ou assincronia entre os requerimentos de acesso à estrutura de oportunidades que brindam o mercado, o Estado e a sociedade civil, e os ativos (os capitais) dos domicílios que permitiriam aproveitar tais oportunidades. Nesse aspecto, apesar de se assumir nessa pesquisa as mesmas variáveis, considerase, como já apontado, essas expressões como resultado da dinâmica do processo de acumulação capitalista e da falta de acesso aos direitos sociais - educação, saúde, acesso ao trabalho e renda, habitação - de modo a enfatizar as responsabilidades do Estado em relação aos seus cidadãos, e não déficits de ativos dos indivíduos, o que leva a uma culpabilização das vítimas (ACSELRAD, 2013). Nesse aspecto, a abordagem teórico-metodológica e a justificativa desenvolvida pelo Ipea se aproxima mais de nossa compreensão. Seguindo a diretiva do IVS produzido pelo Ipea (2015), o IVS aqui apresentado tem a pretensão de sinalizar o acesso, a ausência ou a insuficiência de alguns 
“ativos" em áreas do território do litoral do Paraná, os quais deveriam, a princípio, estar à disposição de todo cidadão, por força da ação do Estado.

Dessa forma, o IVS que foi aplicado ao litoral do Paraná, reproduzindo a metodologia da Fundação Seade, é construído a partir dos dados do Censo 2010 do IBGE, por meio do qual se categorizam os setores censitários em 7 grupos de vulnerabilidade, utilizando-se análise fatorial e tomando por base duas dimensões: a socioeconômica e a demográfica. Optou-se por replicar esse índice por considerar que as dimensões escolhidas do IPVS são aquelas mais relevantes para a percepção da vulnerabilidade social na realidade do litoral do Paraná, amplamente estabelecida na literatura sobre pobreza multidimensional e vulnerabilidade social.

Isso porque algumas metodologias utilizam variáveis, além dos dados socioeconômicos e demográficos, como adequação do domicílio, abastecimento de água da rede, entre outros, que também consideramos relevantes, uma vez que expressam déficits da ação pública no atendimento aos cidadãos que os expõem a determinados tipos de riscos. Porém, como o universo dessa pesquisa - a zona costeira do Paraná - abrange setores rurais e urbanos, considerar essas variáveis implicaria em rebaixar as notas aplicadas aos setores rurais, mas que não decorreria necessariamente em maior vulnerabilidade, pois nas áreas rurais os moradores têm opções alternativas para abastecimento de água, para o esgotamento sanitário e para a destinação do lixo que não têm o mesmo impacto que para os moradores das áreas urbanas (VON KAICK, 2007). Nesse sentido, as duas dimensões mais importantes e de comparação possível entre as realidades urbanas e rurais são, como aqui se entende, as demográficas e socioeconômicas, considerando ainda que os moradores de áreas rurais podem estar envolvidos em outros tipos de relações econômicas e em grande parte dos casos possuem meios de produção (ferramentas de trabalho), ainda que às vezes de forma limitada. Porém, os moradores de áreas urbanas dispõem de maior facilidade de acesso a serviços de saúde, educação, transporte etc., motivo pelo qual se tomou por adequada a manutenção dessas duas dimensões e a comparação de vulnerabilidade entre setores urbanos e rurais a partir destas, com uma diferenciação que se aplica no caso dos setores com alta vulnerabilidade demográfica e socioeconômica, no qual se explicitam as diferenças entre os setores urbanos e rurais, como se verá adiante.

Cabe destacar, outra vez, que se impõe um duplo movimento - sincrônico e diacrônico quantitativo e qualitativo, para uma análise que tome em conta tanto a situação atual de vulnerabilidade, expresso aqui no índice, quanto os elementos processuais e relacionais. Isso porque se entende que um índice de vulnerabilidade social serve para estabelecer uma métrica que permita observar a distribuição desigual da riqueza socialmente produzida em termos espaciais, numa 
determinada escala, nesse caso, regional, com suas divisões intraescalares. Porém, os índices não falam por si próprios e necessitam ser contrastados e interpretados, por meio de triangulação dos dados quantitativos produzidos com informações qualitativas e históricas. Quantificação e qualificação são compreendidas como procedimentos complementares para apreensão do concreto, tal qual explicitado por Lefebvre (1991).

Há que se salientar, ainda, os limites inerentes a tal abordagem. A quantificação a partir de dados secundários é a operação que permite observar o conjunto da situação do litoral paranaense, observando as distinções intraespaciais. Porém, os recortes dos setores censitários são relativamente arbitrários e, nesse sentido, limitam a capacidade de compreender as unidades internas e suas relações. Ainda assim, trata-se de abordagem extremamente útil para uma análise da diferenciação espacial no litoral paranaense, como se pode observar nos resultados gerados.

\section{Operacionalização}

$\mathrm{Na}$ metodologia desenvolvida pela Seade, os setores censitários com pelo menos 50 domicílios particulares permanentes foram classificados em 7 grupos de vulnerabilidade. No caso de nossa pesquisa, utilizaram-se todos os setores censitários do universo, independentemente do número de domicílios. O território do litoral paranaense está dividido em 482 setores censitários, sendo 75 rurais, com uma população de 25.033 habitantes, e 407 setores urbanos contando com 239.121 habitantes (consideram-se apenas os residentes em domicílios particulares permanentes). Foram excluídos 6 setores censitários por apresentarem dados incompletos, 2 no município de Antonina e 4 em Paranaguá. Na Tabela 01, apresentam-se os dados dos setores.

TABELA 01 - SETORES CENSITÁRIOS POR TIPO, SEGUNDO SITUAÇÃO. LITORAL DO PARANÁ - 2010

\begin{tabular}{l|c|c|c|c|c|c|c}
\hline \multicolumn{7}{c}{ Total de setores censitários } \\
\hline & Situação & Total & $\begin{array}{c}\text { Não } \\
\text { especial }\end{array}$ & Subnormal & Domicílios & Moradores & $\begin{array}{c}\text { Média } \\
\text { moradores }\end{array}$ \\
\hline & Total & 482 & 466 & 16 & 80177 & 264154 & 3,29 \\
\hline 1 & Área urbanizada de cidade ou vila & 393 & 377 & 14 & 70942 & 233112 & 3,29 \\
\hline 2 & Área não urbanizada de cidade ou & 14 & 12 & 2 & 1714 & 6009 & 3,51 \\
\hline 3 & vila & - & - & - & - & - & - \\
\hline 4 & Rural de extensão urbana & 1 & 1 & - & 102 & 422 & 4,14 \\
\hline 5 & Rural isolado - povoado & 5 & 5 & - & 490 & 1747 & 3,57 \\
\hline 6 & Rural isolado - núcleo & - & - & - & - & - & - \\
\hline 7 & Rural isolado - outros aglomerados & - & - & - & - & - & - \\
\hline 8 & Rural - exclusive aglomerado rural & 69 & 69 & - & 6929 & 22864 & 3,30 \\
\hline
\end{tabular}

FONTE: (IBGE) 2010. Organizado pela autora. 
Para o levantamento dos dados necessários, foram acessados os dados do Censo Demográfico 2010 para os setores censitários, disponível no sítio eletrônico do IBGE. O cálculo de cada um dos componentes foi realizado a partir dessa fonte, com as variáveis indicadas no Quadro 01, no qual se encontra a fundamentação de escolha e manutenção de cada um dos componentes.

QUADRO 01 - VARIÁVEIS UTILIZADAS NO IVS E FUNDAMENTAÇÃO. BASEADO NO IPVS - SEADE/2013

\begin{tabular}{|c|c|}
\hline COMPONENTE & FUNDAMENTAÇÃO \\
\hline $\begin{array}{l}\text { V1 \% de pessoas responsáveis pelo } \\
\text { domicílio alfabetizadas }\end{array}$ & $\begin{array}{l}\text { Pessoas não alfabetizadas têm acesso a empregos e ocupações com menores rendimentos e } \\
\text { menos oportunidades no mercado de trabalho. }\end{array}$ \\
\hline $\begin{array}{l}\text { V2 \% de pessoas responsáveis de } 10 \\
\text { a } 29 \text { anos }\end{array}$ & $\begin{array}{l}\text { Famílias com responsáveis jovens têm menor estabilidade na ocupação, tendem a ter } \\
\text { rendimentos menores e maior instabilidade. }\end{array}$ \\
\hline $\begin{array}{l}\text { V3 Idade média das pessoas } \\
\text { responsáveis }\end{array}$ & $\begin{array}{l}\text { Famílias com responsáveis jovens têm menor estabilidade na ocupação, tendem a ter } \\
\text { rendimentos menores e maior instabilidade. }\end{array}$ \\
\hline $\begin{array}{l}\text { V4 \% de crianças de } 0 \text { a } 5 \text { anos de } \\
\text { idade }\end{array}$ & Crianças de 0 a 5 anos aumentam a dependência, gastos e exigências de cuidados. \\
\hline $\begin{array}{l}\text { V5 \% de mulheres responsáveis de } \\
10 \text { a } 29 \text { anos de idade }\end{array}$ & $\begin{array}{l}\text { Mulheres têm rendimento menor do que os homens e acumulam as funções de cuidado com } \\
\text { idosos, crianças e do espaço doméstico. Famílias monoparentais implicam maior dificuldade } \\
\text { de absorver mudanças e reagir a situações de risco. }\end{array}$ \\
\hline V6 Renda domiciliar per capita & $\begin{array}{l}\text { Quanto menor a renda, menor a capacidade de ter acesso a meios necessários para a inserção } \\
\text { social e para responder a situações de risco. }\end{array}$ \\
\hline $\begin{array}{l}\text { V7 Rendimento médio da mulher } \\
\text { responsável pelo domicílio }\end{array}$ & $\begin{array}{l}\text { Mulheres responsáveis com rendimentos mais baixos implicam em menor capacidade de } \\
\text { resposta pelo acúmulo de tarefas domésticas e de cuidado, somadas às dificuldades inerentes } \\
\text { da renda, em geral mais baixa que a do homem. }\end{array}$ \\
\hline $\begin{array}{l}\text { V8 \% de domicílios com renda } \\
\text { domiciliar per capita de até } 1 \frac{2}{2} \text { salário } \\
\text { mínimo }\end{array}$ & $\begin{array}{l}\text { Quanto menor a renda, menor a capacidade de ter acesso a meios necessários para a inserção } \\
\text { social e para responder a situações de risco. Famílias com rendimento até } 1 / 2 \text { SM são } \\
\text { vulneráveis à pobreza. }\end{array}$ \\
\hline $\begin{array}{l}\text { V9 \% de domicílios com renda } \\
\text { domiciliar per capita de até } 1 / 4 \text { salário } \\
\text { mínimo }\end{array}$ & $\begin{array}{l}\text { Quanto menor a renda, menor a capacidade de ter acesso a meios necessários para a inserção } \\
\text { social e para responder a situações de risco. Famílias com renda até } 1 / 4 \text { SM são consideradas } \\
\text { em situação de pobreza. }\end{array}$ \\
\hline
\end{tabular}

FONTE: Elaborado pela autora

Após a confecção da base de dados, para a elaboração da parte estatística da pesquisa, contou-se com a assessoria do Laboratório de Estatística Aplicada (Labest), do curso de Estatística da Universidade Federal do Paraná. Foram replicados os procedimentos adotados pela Seade, conforme descritos a seguir.

Inicialmente, procedeu-se a estatística descritiva dos dados do universo. Na Tabela 02 encontram-se as variáveis coletadas com as respectivas média, desvio padrão e número de observações por variável. 
TABELA 02 - ESTATÍSTICA DESCRITIVA

\begin{tabular}{lccc}
\hline \multicolumn{1}{c}{ Variável } & Média & Desvio Padrão & N \\
\hline V1 (\% de pessoas responsáveis pelo domicílio alfabetizadas) & 93,85 & 6,21 & 476 \\
\hline V2 (\% de pessoas responsáveis de 10 a 29 anos) & 13,13 & 6,00 & 476 \\
\hline V3 (Idade média das pessoas responsáveis) & 47,28 & 3,77 & 476 \\
\hline V4 (\% de crianças de 0 a 5 anos de idade) & 8,81 & 2,35 & 476 \\
\hline V5 (\% de mulheres responsáveis de 10 a 29 anos de idade) & 12,74 & 9,20 & 476 \\
\hline V6 (Renda domiciliar per capita) & 660,93 & 384,11 & 476 \\
\hline V7 (Rendimento médio da mulher responsável pelo domicílio) & 879,23 & 512,29 & 476 \\
\hline V8 (\% de domić́lios com renda domiciliar per capita de até 1/4 salário mínimo) & 6,95 & 7,82 & 476 \\
\hline V9 (\% de domicílios com renda domiciliar per capita de até 1/2 salário mínimo) & 22,67 & 14,08 & 476 \\
\hline FONTE: (IBGE) 2010. Dados organizados pela autora, tratados pelo Labest/UFPR. & &
\end{tabular}

Em seguida, foi realizada a matriz de correlação entre as variáveis utilizadas na pesquisa, conforme Tabela 03 .

TABELA 03 - MATRIZ DE CORRELAÇÃO

\begin{tabular}{c|c|c|c|c|c|c|c|c|c|}
\hline & V1 & V2 & V3 & V4 & v5 & v6 & v7 & v8 & v9 \\
\hline V1 & 1 & & & & & & & & \\
\hline V2 & $-0,13$ & 1 & & & & & & & \\
\hline V3 & 0,06 & $-0,78$ & 1 & & & & & & \\
\hline V4 & $-0,33$ & 0,5 & $-0,65$ & 1 & & & & & \\
\hline V5 & $-0,11$ & 0,69 & $-0,5$ & 0,33 & 1 & & & & \\
\hline V6 & 0,52 & $-0,33$ & 0,41 & $-0,55$ & $-0,14$ & 1 & & & \\
\hline V7 & 0,45 & $-0,39$ & 0,43 & $-0,51$ & $-0,29$ & 0,85 & 1 & & \\
\hline V8 & $-0,68$ & 0,2 & $-0,18$ & 0,39 & 0,08 & $-0,55$ & $-0,46$ & 1 & \\
\hline V9 & $-0,72$ & 0,28 & $-0,33$ & 0,56 & 0,13 & $-0,75$ & $-0,65$ & 0,87 & 1 \\
\hline
\end{tabular}

FONTE: (IBGE) 2010. Dados organizados pela autora, tratados pelo Labest/UFPR.

De acordo com Rencher (2002), recomenda-se que, para obter resultados satisfatórios, o KMO deve estar próximo de 0,8. Para os dados em questão, obteve-se $\mathrm{KMO}=0,78$, sendo, portanto, adequado. O Teste de Esfericidade de Bartlett é utilizado para verificar se a matriz de correlação é próxima da identidade, implicando que as variáveis são não correlacionadas. Ao aplicar esse teste aos dados, obteve-se p-valor <0,001, ou seja, os dados são significativamente correlacionados.

Após aplicar o Método de Componentes Principais na matriz de correlação dos dados, obteve-se o percentual de explicação por componente principal. Para prosseguir com a Análise Fatorial Exploratória por meio do Método de Componentes Principais, e com base no Critério de 
Kaiser, foram escolhidas duas componentes para representar a quantidade de fatores, pois há apenas duas componentes com autovalores maiores do que 1 , representando $73,4 \%$ da variação dos dados, conforme a Tabela 04.

TABELA 04 - PERCENTUAL DE EXPLICAÇÃO

\begin{tabular}{cccc}
\hline & Autovalores & \% explicação por componente & \% explicação acumulado \\
\hline V1 & 4,6 & 51,2 & 51,2 \\
\hline V2 & 2,0 & 22,2 & 73,4 \\
\hline V3 & 0,8 & 8,7 & 82,1 \\
\hline V4 & 0,6 & 6,7 & 88,8 \\
\hline V5 & 0,4 & 4,2 & 93,0 \\
\hline V6 & 0,3 & 3,2 & 96,2 \\
\hline V7 & 0,2 & 1,7 & 97,8 \\
\hline V8 & 0,1 & 1,3 & 99,1 \\
\hline V9 & 0,1 & 0,9 & 100,0 \\
\hline FONTE (IBGE) 2010. & Dados organizados pela autora tratados pelo L best/UFPR
\end{tabular}

A partir da definição dos fatores foram gerados dois escores fatoriais, representando o fator socioeconômico (Fator 1) e o fator demográfico (Fator 2). Os escores fatoriais são médias ponderadas das variáveis originais, expressos em uma escala com média zero e variância 1. No fator socioeconômico, valores maiores na escala indicam maior nível de renda no setor censitário, e no fator demográfico, os maiores valores da escala indicam a maior presença de responsáveis jovens e crianças com menos de cinco anos no setor. Utilizou-se a rotação Varimax para definir melhor os carregamentos das variáveis em cada fator.

A Tabela 05 apresenta o conjunto de variáveis associadas a cada fator e o valor da correlação da variável (cargas fatoriais) com o fator correspondente. Assim, ao fator socioeconômico estão associadas as variáveis: renda domiciliar per capita (RDPC), proporção de domicílios com renda domiciliar per capita de até meio salário mínimo (SM), proporção de domicílios com renda domiciliar per capita de até um quarto do salário mínimo, rendimento médio da mulher responsável pelo domicílio e proporção de pessoas responsáveis alfabetizadas. Ao fator demográfico estão associadas as variáveis: proporção de pessoas responsáveis de 10 a 29 anos, proporção de mulheres responsáveis de 10 a 29 anos, idade média das pessoas responsáveis e proporção de crianças de 0 a 5 anos de idade. Os escores fatoriais foram estimados pelo método de mínimos quadrados ponderados. 


\begin{tabular}{lcc}
\hline \multicolumn{1}{c}{ Variável } & Fator 1 & Fator 2 \\
\hline V1 (\% de pessoas responsáveis pelo domicílio alfabetizadas) & $\mathbf{0 , 8 2}$ & 0,04 \\
\hline V2 (\% de pessoas responsáveis de 10 a 29 anos) & $-0,12$ & $\mathbf{0 , 9 0}$ \\
\hline V3 (Idade média das pessoas responsáveis) & 0,18 & $\mathbf{- 0 , 8 8}$ \\
\hline V4 (\% de crianças de 0 a 5 anos de idade) & $-0,50$ & $\mathbf{0 , 6 1}$ \\
\hline V5 (\% de mulheres responsáveis de 10 a 29 anos de idade) & 0,01 & $\mathbf{0 , 7 9}$ \\
\hline V6 (Renda domiciliar per capita) & $\mathbf{0 , 8 1}$ & $-0,31$ \\
\hline V7 (Rendimento médio da mulher responsável pelo domicílio) & $\mathbf{0 , 7 0}$ & $-0,41$ \\
\hline V8 (\% de domicílios com renda domiciliar per capita de até 1/2 salário mínimo) & $\mathbf{- 0 , 8 6}$ & 0,02 \\
\hline V9 (\% de domicílios com renda domiciliar per capita de até 1/4 salário mínimo) & $\mathbf{- 0 , 9 4}$ & 0,17 \\
\hline FONTE (IBGE) 2010 Dados on
\end{tabular}

FONTE: (IBGE) 2010. Dados organizados pela autora, tratados pelo Labest/UFPR.

Posteriormente, foi utilizado o método de agrupamento não hierárquico das k-médias. Segundo Anderberg (1973 apud IGNÁCIO, 2002), esse é o método mais usual e baseia-se em duas premissas básicas: coesão interna das unidades observacionais e isolamento externo entre os grupos. O cálculo das distâncias entre as unidades observacionais baseia-se na distância Euclidiana. Parte-se do princípio de que a similaridade entre uma unidade observacional e outra (em um plano, por exemplo) é dada pela distância entre essas duas unidades observacionais, segundo a posição que cada uma ocupa nos dois eixos, medida por qualquer variável considerada significativa para o processo de diferenciação entre as unidades observacionais.

Foram construídas três categorias de perfil socioeconômico: baixa, média e alta (na versão da Seade, as faixas eram baixa, média e muito alta - alteradas considerando a realidade socioeconômica do litoral). Já o fator demográfico foi dividido em duas categorias: famílias jovens e famílias adultas e idosas (Quadro 02).

\section{QUADRO 2 - OPERACIONALIZAÇÃO DOS GRUPOS DO IVS}

\begin{tabular}{|l|l|l|}
\hline \multirow{2}{*}{ Fator socioeconômico } & Fator demográfico \\
\cline { 2 - 3 } & Famílias adultas e idosas - menor que 0,18 & Famílias jovens - maior que 0,18 \\
\hline Alto - maior de 0,35 & Muito baixa vulnerabilidade & \\
\hline Médio - entre -1,08 e 0,35 & Vulnerabilidade baixa & $\begin{array}{l}\text { Vulnerabilidade média } \\
\text { altíssima }\end{array}$ \\
\hline Baixo - menor que -1,08 & Vulnerabilidade alta & muito alta e \\
\hline
\end{tabular}

FONTE: Adaptado de SEADE (2013).

O cruzamento desses cinco grupos com a informação do tipo de setor censitário (subnormal ou não especial) e sua localização na área do município (urbano ou rural) gerou os sete grupos do IVS 2010 (Quadro 3). Alteramos as classificações de vulnerabilidade em relação à metodologia da 
Seade. Excluímos a categoria de baixíssima vulnerabilidade e adicionamos uma categoria de altíssima vulnerabilidade.

QUADRO 03 - GRUPOS DO IVS LITORAL DO PARANÁ - 2010

\begin{tabular}{|c|l|l|l|l|}
\hline \multirow{2}{*}{ Grupos } & \multicolumn{2}{|c|}{ Dimensões } & \multicolumn{1}{c|}{ IVS } & Situação e tipos de setores \\
\cline { 2 - 5 } & Socioeconômica & \multicolumn{1}{|c|}{ Ciclo de vida familiar } & $\begin{array}{l}\text { Vulnerabilidade muito } \\
\text { baixa }\end{array}$ & $\begin{array}{l}\text { Urbanos e rurais não } \\
\text { especiais e subnormais }\end{array}$ \\
\hline 1 & Alta & Famílias jovens, adultas e idosas & Vulnerabilidade baixa & $\begin{array}{l}\text { Urbanos e rurais não } \\
\text { especiais e subnormais }\end{array}$ \\
\hline 3 & Baixa & Famílias adultas e idosas & Vulnerabilidade média & $\begin{array}{l}\text { Urbanos e rurais não } \\
\text { especiais e subnormais }\end{array}$ \\
\hline 4 & Muito baixa & Famílias adultas e idosas & Vulnerabilidade alta & $\begin{array}{l}\text { Urbanos não especiais e } \\
\text { subnormais }\end{array}$ \\
\hline 5 & Muito baixa & $\begin{array}{l}\text { Famílias jovens em setores } \\
\text { urbanos }\end{array}$ & Vulnerabilidade muito alta & Urbanos não especiais \\
\hline 6 & Muito baixa & $\begin{array}{l}\text { Famílias jovens residentes em } \\
\text { aglomerados subnormais }\end{array}$ & Vulnerabilidade altíssima & Urbanos subnormais \\
\hline 7 & Muito baixa & $\begin{array}{l}\text { Famílias jovens, adultas e idosas } \\
\text { em setores rurais }\end{array}$ & Vulnerabilidade muito alta & Rurais \\
\hline
\end{tabular}

FONTE: Elaborado pela autora.

Há que se destacar que a análise fatorial aplicada apenas aos setores censitários dos municípios do litoral do Paraná serve apenas para compará-los entre si. Ou seja, essas métricas expressam a vulnerabilidade dos setores censitários tendo como horizonte apenas o litoral do Paraná e sua realidade socioeconômica e demográfica. Caso se utilizasse os dados de todos os municípios do Paraná, como foi feito no IPVS, os resultados seriam distintos, uma vez que os valores do universo seriam também diferentes.

\section{Resultados}

Ao observar os resultados gerados pela aplicação da metodologia de construção do IVS, optou-se por apresentá-los separando as áreas urbanas e rurais. Isso porque as diferenças pareceram bastante relevantes e separá-las permitiria um tratamento mais adequado dessas diferenças. Buscouse analisar, ainda que de forma preliminar, os resultados à luz das informações existentes sobre as dinâmicas históricas, econômicas e políticas do litoral do Paraná, tanto em dados secundários de outras fontes quanto na literatura acadêmica disponível. 


\section{A vulnerabilidade social nas áreas rurais}

Nas áreas rurais dos municípios do litoral residem 25.163 pessoas, em 7.483 domicílios. Isso corresponde a cerca de $9,5 \%$ da população residente no litoral. Em que pese representar pouco em termos populacionais, em termos espaciais ocupa quase $94 \%$ do território ${ }^{2}$, com $5.683,37 \mathrm{~km}^{2}$. É, portanto, uma área de baixa densidade demográfica, na qual mais de 50\% da população vive em áreas que são caracterizadas pela vulnerabilidade social muito alta (Tabela 06). Nesses setores, a renda domiciliar per capita (RDPC) era de, em média, $\mathrm{R} \$ 273,56$, e a taxa de domicílios com RDPC de até 1/2 salário mínimo (SM) era de 50,35\% e até 1/4 de salário mínimo era de 24,76\%. O nível de responsáveis não alfabetizados é bastante elevado, uma vez que apenas cerca de $80 \%$ destes é alfabetizado (a taxa média para o Brasil no Censo 2010 foi de 91\%).

Há apenas dois setores que se enquadraram na vulnerabilidade muito baixa. Um deles é a área referente à praia de Nova Brasília, na Ilha do Mel, em Paranaguá, onde residem 63 pessoas em 25 domicílios, caracterizada por seu uso turístico. Outro está localizado em Morretes, na região de Serra, fazendo frente com a BR-277 (Figura 01), na qual residem 48 pessoas em 18 domicílios, com idade média do chefe do domicílio superior à média e com uma renda per capita bem superior à média dos setores rurais, alcançando $\mathrm{R} \$ 963,40$ (Tabela 06).

O restante da população rural está distribuído entre as áreas de baixa vulnerabilidade $32,29 \%$, e média vulnerabilidade $-9,72 \%$. Os índices dessas duas categorias são bastante similares em termos de alfabetização do responsável, ambas na casa dos 90\%, bem como na RDPC, que se encontram na faixa dos $R \$ 450,00$. A principal diferença está no ciclo de vida familiar: enquanto os setores rurais de baixa vulnerabilidade são compostos por famílias adultas ou idosas, com idade média do responsável de aproximadamente 49 anos e pouco mais de $11 \%$ de responsáveis de até 29 anos, os setores de média vulnerabilidade são constituídos por famílias com idade média de 44 anos, possuem um percentual maior de responsáveis de até 30 anos e de crianças de até 5 anos.

\footnotetext{
${ }^{2}$ Dados calculados pelo programa de informações geográficas com base nas malhas do IBGE.
} 
TABELA 06 - SÍNTESE DAS VARIÁVEIS POR CATEGORIA DO IVS - SETORES RURAIS

\begin{tabular}{lccccccccccc}
\hline Vulnerabilidade & DPP & RDPP & V1 & V2 & V3 & V4 & V5 & V6 & V7 & V8 & V9 \\
\hline Muito baixa & 43 & 111 & 84,55 & 11,81 & 50,73 & 6,52 & 11,81 & 963,4 & 1430,1 & 9,26 & 1,85 \\
\hline Baixa & 0,57 & 0,45 & & & & & & & & & \\
\hline \multicolumn{1}{c}{} & 2948 & 9551 & 90 & 11,16 & 48,94 & 8,57 & 11,16 & 441,55 & 917,8 & 28,68 & 7,8 \\
\hline Média & 39,4 & 38,29 & & & & & & & & & \\
\hline \multicolumn{1}{c}{} & 748 & 2424 & 89,36 & 18,87 & 44,52 & 9,77 & 18,87 & 459,47 & 928,18 & 28,2 & 8,51 \\
\hline Muito alta & 10 & 9,72 & & & & & & & & & \\
\hline TOTAL & 3744 & 12855 & 80,22 & 11,83 & 48,15 & 9,57 & 11,83 & 273,56 & 576,43 & 50,65 & 24,76 \\
\hline
\end{tabular}

FONTE: Elaborado pela autora a partir dos dados do IBGE (2010). Permanentes.

NOTA: DPP - Domić́lios Particulares Permanentes; RDPP - Residentes em Domicílios Particulares

Ao se observar a distribuição pelos municípios, Antonina e Guaraqueçaba apresentam o maior número de setores rurais com vulnerabilidade muito alta (Tabela 07). Dos 8 setores de Antonina, apenas 1 apresenta média vulnerabilidade, na região de Cachoeira de Cima. Isso representa que $89 \%$ da população rural do município vive em áreas de vulnerabilidade muito alta, auferindo uma renda domiciliar per capita de cerca de $\mathrm{R} \$ 336,00$ e com cerca de $44 \%$ dos domicílios com RDPC de até 1⁄2 salário mínimo. Já em Guaraqueçaba, 98\% da população rural está em áreas de muito alta vulnerabilidade, com uma RDPC de R\$224,09 e cerca de 58\% dos domicílios com RDPC de até 1/2 SM. O único setor rural de Guaraqueçaba que possui média vulnerabilidade é o que corresponde à localidade de Serra Negra.

Os municípios de Paranaguá, Morretes e Guaratuba são os que possuem maior heterogeneidade na vulnerabilidade social das áreas rurais. Em Paranaguá, 62,7\% dos residentes na área rural vivem em domić́lios localizados em setores com vulnerabilidade baixa e 20,4\% em setores com vulnerabilidade muito alta. Já em Morretes, $67 \%$ dos residentes vivem em áreas de baixa vulnerabilidade, enquanto 30,7\% vivem em área de vulnerabilidade muito alta.

Guaratuba, por sua vez, tem $22 \%$ da sua população rural em situação de baixa vulnerabilidade social, $34,5 \%$ em média e $43,5 \%$ em vulnerabilidade social muito alta. Portanto, é menos heterogênea e mais vulnerável do que a população rural de Morretes e Paranaguá. 
TABELA 07 - RESULTADOS DO IVS POR MUNICÍPIO - SETORES RURAIS

\begin{tabular}{|c|c|c|c|c|c|c|c|c|c|c|c|c|c|c|c|}
\hline & \multicolumn{3}{|c|}{ Muito baixa } & \multicolumn{3}{|c|}{ Baixa } & \multicolumn{3}{|c|}{ Média } & \multicolumn{3}{|c|}{ Muito alta } & \multicolumn{3}{|c|}{ Total } \\
\hline & Setor & DPP & RDPP & Setor & DPP & RDPP & Setor & DPP & RDPP & Setor & DPP & RDPP & Setor & DPP & RDPP \\
\hline \multirow[t]{2}{*}{ Antonina } & & & & & & & 1 & 97 & 300 & 8 & 734 & 2442 & 9 & 831 & 2742 \\
\hline & & & & & & & 11,1 & 11,7 & 10,9 & 88,9 & 88,3 & 89,1 & 100,0 & 100,0 & 100,0 \\
\hline \multirow[t]{2}{*}{ Guaraqueçaba } & & & & & & & 1 & 29 & 81 & 14 & 1478 & 5102 & 15 & 1507 & 5183 \\
\hline & & & & & & & 6,7 & 1,9 & 1,6 & 93,3 & 98,1 & 98,4 & 100,0 & 100,0 & 100,0 \\
\hline \multirow[t]{2}{*}{ Guaratuba } & & & & 3 & 202 & 722 & 2 & 314 & 1132 & 4 & 439 & 1429 & 9 & 955 & 3283 \\
\hline & & & & 33,3 & 21,2 & 22,0 & 22,2 & 32,9 & 34,5 & 44,4 & 46,0 & 43,5 & 100,0 & 100,0 & 100,0 \\
\hline \multirow[t]{2}{*}{ Matinhos } & & & & 1 & 17 & 56 & & & & 1 & 24 & 88 & 2 & 41 & 144 \\
\hline & & & & 50,0 & 41,5 & 38,9 & & & & 50,0 & 58,5 & 61,1 & 100,0 & 100,0 & 100,0 \\
\hline \multirow[t]{2}{*}{ Morretes } & 1 & 18 & 48 & 11 & 1786 & 5702 & 1 & 44 & 146 & 1 & 725 & 2618 & 14 & 2573 & 8514 \\
\hline & 7,1 & 0,7 & 0,6 & 78,6 & 69,4 & 67,0 & 7,1 & 1,7 & 1,7 & 7,1 & 28,2 & 30,7 & 100,0 & 100,0 & 100,0 \\
\hline \multirow[t]{2}{*}{ Paranaguá } & 1 & 25 & 63 & 8 & 943 & 3071 & 3 & 264 & 765 & 4 & 295 & 999 & 16 & 1527 & 4898 \\
\hline & 6,3 & 1,6 & 1,3 & 50,0 & 61,8 & 62,7 & 18,8 & 17,3 & 15,6 & 25,0 & 19,3 & 20,4 & 100,0 & 100,0 & 100,0 \\
\hline \multirow[t]{2}{*}{ Pontal do Paran } & & & & & & & & & & 1 & 49 & 177 & 1 & 49 & 177 \\
\hline & & & & & & & & & & & 100,00 & 100,00 & & 100,00 & 100,00 \\
\hline \multirow[t]{2}{*}{ Total } & 2 & 43 & 111 & 23 & 2948 & 9551 & 8 & 748 & 2424 & 32 & 3695 & 12678 & 65 & 7434 & 24764 \\
\hline & 3,1 & 0,6 & 0,4 & 35,4 & 39,7 & 38,6 & 12,3 & 10,1 & 9,8 & 49,2 & 49,7 & 51,2 & 100,0 & 100,0 & 100,0 \\
\hline
\end{tabular}

FONTE: Elaborado pela autora a partir dos dados do IBGE (2010).

Pontal do Paraná e Matinhos possuem população rural muito pequena. Em Matinhos, há dois setores, um com baixa vulnerabilidade e outro com vulnerabilidade muito alta, juntos somando 144 residentes. Já Pontal do Paraná possui apenas 1 setor rural, de vulnerabilidade muito alta, que conta com 177 residentes.

Explicar o conjunto da variabilidade espacial da vulnerabilidade social nos setores rurais transcende o escopo deste artigo, uma vez que seriam necessárias maiores informações além daquelas produzidas pelo índice em si. Contudo, podemos destacar elementos que parecem contribuir para a diferente distribuição da vulnerabilidade social entre os setores rurais dos municípios, com base em outros dados secundários e na produção bibliográfica existente sobre a região (MARCHIORO, 2002A; MARCHIORO, 2002B; RODRIGUES et al., 2003; SAMPAIO, 2006; BORSATTO et al., 2007; BIASSIO, 2011; FERREIRA et al., 2011; entre outros).

Em primeiro lugar, pode-se considerar as limitantes naturais para o desenvolvimento das atividades produtivas agropecuárias, especialmente o potencial de produção agrícola. Sabe-se, como aponta Marchioro (2002a), que as áreas situadas nas planícies de restingas e manguezais têm baixo 
potencial, que áreas de serra com declividade acentuada são pouco aptas ao uso agrícola e que as adequadas seriam aquelas que possuem vales de rios com boa aptidão para a agricultura.

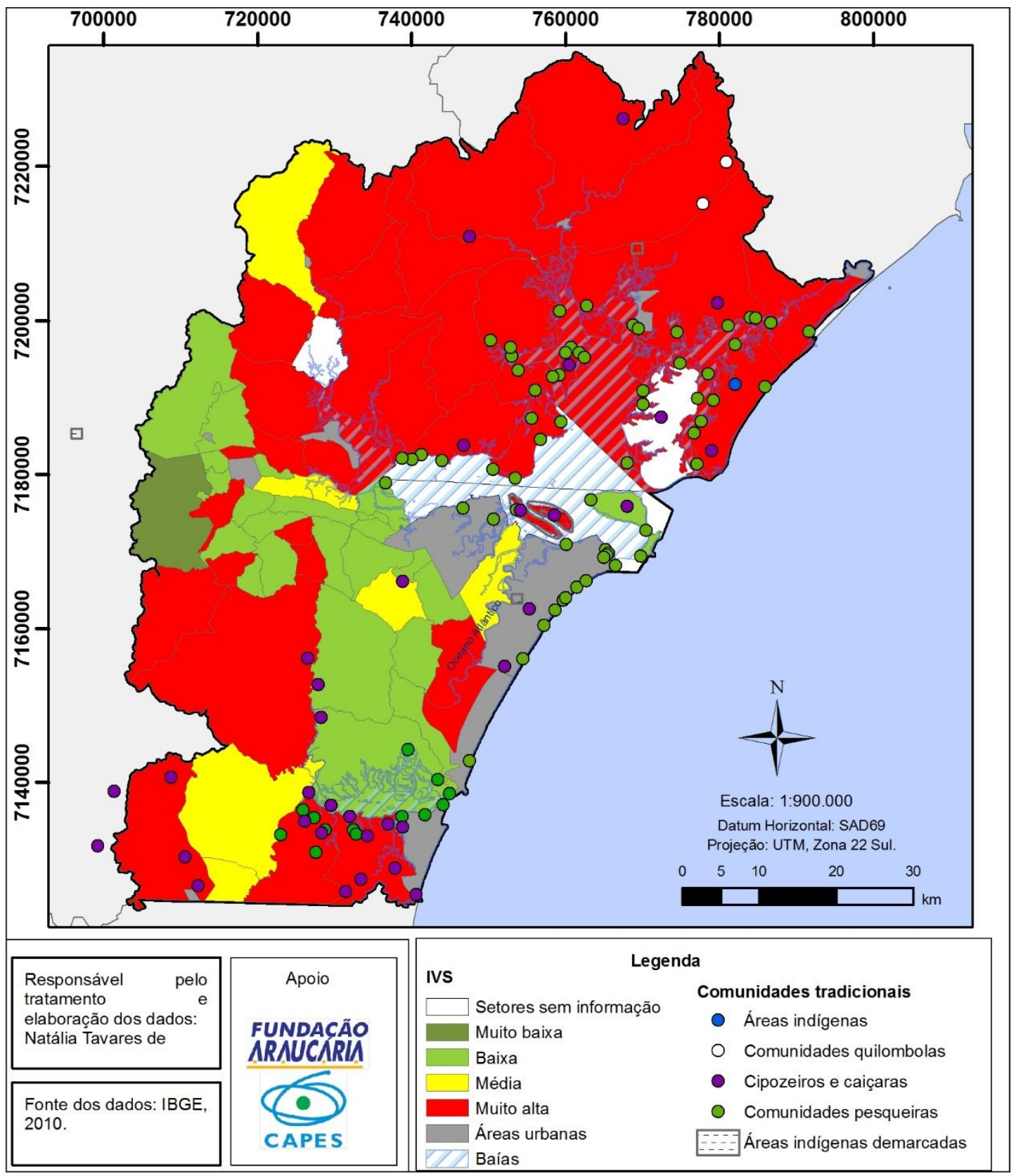

FIGURA 01 - ÍNDICE DE VULNERABILIDADE SOCIAL DOS SETORES RURAIS

As condições naturais, porém, não determinam o desenvolvimento das atividades econômicas, apenas oferecem o quadro a partir do qual possíveis atividades econômicas podem se desenvolver, a depender das forças sociais presentes em determinado momento histórico, dos níveis de riqueza e tecnologia. Importa saber como se inserem nas relações sociais de produção os 
agricultores do litoral paranaense, produzindo quais tipos de produtos, com quais tecnologias e condições de competitividade e com que tipo de relações de trabalho.

Nesse sentido, merece ser destacada a produção agropecuária e o tipo de organização social presente para produzi-la. O primeiro aspecto a ser ressaltado é que, considerando as 39 microrregiões nas quais está dividido administrativamente o estado do Paraná, a de Paranaguá é a última colocada em termos do valor adicionado da agropecuária (dados do Ipardes referentes ao ano de 2013). Dito isso, grosso modo, como se pode observar na Tabela 08, em 2013 Morretes foi o município com o maior valor adicionado no setor agropecuário, ultrapassando Guaratuba ${ }^{3}$. Contudo, ao se considerar a população, o valor adicionado per capita (cálculo realizado com base na população rural de cada município) de Guaratuba é superior ao de Morretes. Guaratuba possui uma agricultura mais concentrada na bananicultura, na mandioca e no arroz, enquanto Morretes possui uma pauta mais diversificada, com olericultura, maracujá, mandioca, banana, gengibre, entre outros (MARCHIORO, 2002a; SEAB/DERAL, 2014).

Antonina teve menor valor adicionado, ficando à frente apenas de Paranaguá, mas com melhor desempenho do que Guaraqueçaba no valor per capita. Guaraqueçaba, por sua vez, embora seja, assim como Morretes, um município predominantemente rural, apresentou um decréscimo em seu valor adicionado no setor agropecuário, e seu valor per capita só ficou acima do de Paranaguá. Paranaguá confirma o uso predominante de moradia e lazer de sua área rural, tendo em vista o baixo valor adicionado do setor agropecuário. Matinhos e Pontal do Paraná possuem produção agropecuária de pouca significância.

Em relação à Guaraqueçaba, cabe salientar que a região foi particularmente pujante em sua agricultura até a década de 1930 (MIGUEL, 1997). Porém, sabe-se, como apontaram Rodrigues et al. (2003), que uma série de condicionantes levaram à situação de insustentabilidade da agricultura em Guaraqueçaba - um processo histórico de concentração fundiária, resultado de políticas de incentivo fiscal para atividades agroflorestais na década de 1970, restrições ambientais devido às unidades de conservação, isolamento geográfico e falta de estradas para o escoamento da produção, falta de recursos econômicos e de políticas públicas para manter uma agricultura com condição de inserção no mercado, entre outros. O resultado é a semiproletarização e o empobrecimento da população.

\footnotetext{
${ }^{3}$ Se levarmos em consideração o valor bruto da produção levantado pela Secretaria de Estado da Agricultura e Abastecimento, em Guaratuba o valor bruto da produção em 2014 foi de quase 113 milhões de reais, enquanto o de Morretes foi em torno de 40 milhões. Contudo, mantivemos os dados do Valor Adicionado utilizados para o cálculo do PIB.
} 
TABELA 08 - VALOR ADICIONADO A PREÇOS BÁSICOS - AGROPECUÁRIA

\begin{tabular}{lcccccc}
\hline & 2010 & 2011 & 2012 & 2013 & Pop. & VAPC2013 \\
\hline Antonina & 7.114 & 7.093 & 9.547 & 12.504 & 2742 & $4.560,18$ \\
\hline Guaraqueçaba & 24.282 & 17.237 & 18.734 & 18.938 & 5183 & $3.653,87$ \\
\hline Guaratuba & 22.560 & 19.652 & 22.991 & 31.626 & 3283 & $9.633,26$ \\
\hline Morretes & 23.836 & 29.122 & 29.661 & 42.304 & 8514 & $4.968,76$ \\
\hline Paranaguá & 5.212 & 5.486 & 5.274 & 7.215 & 4898 & $1.473,05$ \\
\hline $\begin{array}{l}\text { FONTE: IPARDES }(2015) . \\
\text { NOTA: Em R } \$ \text { 1.000,00 VAPC - Valor adicionado per capita em R } \$ 1,00 .\end{array}$
\end{tabular}

A produção agrícola se dá a partir de condições diferenciadas entre as propriedades, com tecnologias e formas de organização da produção distintas. Marchioro (2002a) identificou 4 categorias de situações técnicas agrícolas nas unidades que definiu no litoral do Paraná (23 bacias hidrográficas): áreas com ocorrências esporádicas de agricultura, modelo tecnológico em transformação, agricultura tradicional produtiva e agricultura tecnificada produtiva. Observando esse critério, as áreas com as melhores condições na perspectiva da vulnerabilidade social, com a maior parte das áreas consideradas de baixa vulnerabilidade social, são as Bacias do Marumbi e do Rio Sagrado, situadas em Morretes, que possuem um modelo tecnológico em transformação e ao mesmo tempo, segundo Marchioro (2002a), uma situação fundiária de baixa concentração de terras e sem conflitos aparentes. Ademais, há situações também melhores na Bacia do Alto Cachoeira, em Antonina, que corresponde ao setor de vulnerabilidade média no município e que segundo Marchioro (2002a) apresenta agricultura tradicional produtiva e estrutura fundiária com baixo nível de concentração, bem como em Guaratuba, na bacia do Rio Cubatão, onde se pratica agricultura tecnificada e com médios níveis de concentração de terra, no qual a vulnerabilidade é média. Em que pese a diferença temporal dos dados, a sugestão da forte correlação entre eles nos sugere que são informações que merecem ser aprofundadas, compreendendo a relação entre as dinâmicas econômicas, tecnológicas e sociais (sem falar nas ambientais, que não estão enfocadas neste artigo).

Há que se lembrar, porém, que nem todos os setores rurais têm uso necessário ou exclusivamente agrário: há propriedades onde as famílias são pluriativas, nas quais ocorre assalariamento de alguns membros das famílias, compondo a renda com atividades agrícolas e não agrícolas (semiproletarização); há aquelas em que, apesar da moradia em área rural, não há uso agrícola, e especificamente no cenário costeiro, setores considerados rurais que abrigam comunidades que hoje são predominante ou exclusivamente pesqueiras, como ocorre com várias localizadas no complexo estuarino-lagunar de Paranaguá (ANDRIGUETTO FILHO, 1999) e 
algumas na Baía de Guaratuba, embora possam ter origem agrícola, além de comunidades indígenas e quilombolas.

Levando em conta os usos não agrícolas do meio rural, identificou-se certa tendência nas áreas rurais de que os setores com melhor situação em relação à vulnerabilidade social são aqueles que possuem, percentualmente em relação ao próprio setor, o maior número de domicílios de uso ocasional, voltados ao lazer, geralmente sítios e chácaras. Enquanto nos setores rurais com Alta Vulnerabilidade cerca de $27 \%$ dos domicílios são de uso ocasional, no de Média Vulnerabilidade é de 23,5\%, no de Baixa Vulnerabilidade é de 32\% e nos de Muito Baixa Vulnerabilidade é de 44,6\% (Tabela 09). Isso poderia ser resultado de uma tendência de ocupação do espaço rural que concentra áreas para o lazer e a residência de pessoas aposentadas ou de uma faixa etária maior que buscam melhor qualidade de vida no meio rural. Essas hipóteses devem ser confirmadas por meio de pesquisas empíricas e a relação entre a comunidade nativa e os migrantes investigada. Na Tabela 09, que apresenta as quantidades e os percentuais de domicílios de uso ocasional (percentual de domicílios de uso ocasional em relação ao total de domicílios particulares no setor) por município e por faixa de vulnerabilidade, pode-se observar que essa lógica, embora não corresponda a todas as situações, é particularmente observável em Paranaguá, Morretes e Guaratuba, que também contam com os maiores números totais de domicílios de uso ocasional.

TABELA 09 - QUANTIDADE E PERCENTUAL DE DOMICÍLIOS DE USO OCASIONAL NOS SETORES

\begin{tabular}{|c|c|c|c|c|c|}
\hline \multicolumn{6}{|c|}{ RURAIS } \\
\hline & $\begin{array}{l}\text { Muito } \\
\text { baixa }\end{array}$ & Baixa & Média & Muito alta & Total \\
\hline Antonina & & & 59 & 369 & 428 \\
\hline$\%$ no setor & & & 32,07 & 28,74 & \\
\hline Guaraqueçaba & & & 10 & 549 & 559 \\
\hline$\%$ no setor & & & 22,22 & 23,75 & \\
\hline Guaratuba & & 359 & 52 & 207 & 618 \\
\hline$\%$ no setor & & 62,43 & 12,24 & 29,20 & \\
\hline Matinhos & & 17 & & 15 & 32 \\
\hline$\%$ no setor & & 36,67 & & 31,25 & \\
\hline Morretes & 12 & 255 & 816 & 20 & 848 \\
\hline$\%$ no setor & 36,36 & 43,97 & 28,65 & 28,57 & \\
\hline Paranaguá & 28 & 461 & 122 & 322 & 933 \\
\hline$\%$ no setor & 52,83 & $\mathbf{3 0 , 3 5}$ & 29,47 & 49,92 & \\
\hline Pontal do Paraná & & & & 23 & 23 \\
\hline$\%$ no setor & & & & 27,38 & \\
\hline Média na categoria & 44,6 & 32,29 & 23,5 & 27,1 & \\
\hline Total & 40 & 1092 & 1059 & 1482 & 3673 \\
\hline$\%$ & 1,09 & 29,73 & 28,83 & 40,35 & 100,00 \\
\hline
\end{tabular}

FONTE: Elaborado pela autora a partir dos dados do IBGE (2010). 
Sampaio e Zamignan (2011), em estudo sobre o desenvolvimento do turismo comunitário da região do Rio Sagrado, apontam que mais da metade dos 520 domicílios nas localidades são de uso ocasional. Outro estudo interessante sobre essa região é o de Gomes et al. (2015), que expõe os processos de mudanças e heterogeneidades na região a partir do incremento de chácaras de uso de lazer (ocasionais), por um lado, e de empreendimentos agrícolas de agentes externos, baseado em sistemas produtivos tecnificados, por outro, em face da comunidade nativa, que mantém o cultivo de banana e mandioca tradicional. A conjunção desses fenômenos parece ter uma dinâmica significativa nas áreas rurais de Guaratuba e Morretes e merecem maior investigação.

Parece pertinente apontar que boa parte dos setores rurais estão localizados nas áreas do Complexo Estuarino de Paranaguá e na Baía de Guaratuba, abrigando comunidades pesqueiras e comunidades caiçaras rurais (FERREIRA et al., 2011). Não se irá aprofundar nessas comunidades neste artigo, uma vez que será feito em outro texto específico, porém, dá-se destaque a esse fato, pois, como se pode observar no mapa (Figura 01), a grande maioria das comunidades pesqueiras situadas nos setores rurais está em área de vulnerabilidade social muito alta, dando relevância ao estudo sobre a relação entre pesca, pobreza e vulnerabilidade, reconhecido amplamente na literatura internacional (BÉNÉ, 2003; 2010).

Vale ressaltar, ainda, que uma série de estudos e iniciativas tem sido realizada nos últimos anos no litoral do Paraná. Registra-se a busca de valorização das farinheiras tradicionais (DENARDIN, 2015), do fortalecimento do uso dos produtos florestais não madeireiros (FERREIRA et al., 2011), da agroecologia (CAVALLET et al., 2013; ROCHA, 2013) e dos sistemas agroflorestais (SEOANE et al., 2013; SALMON et al., 2013; KAMINSKI, 2014), o desenvolvimento de feiras e redes de comercialização agroecológicas (SANTOS et al., 2013). Todas essas iniciativas têm em comum uma busca de construção de um modelo alternativo de desenvolvimento territorial rural no litoral do Paraná, e os autores dos estudos têm apontado para os resultados positivos dessas iniciativas.

Por fim, pode-se apontar que um conjunto de forças concorre para o fato de que grande parte da população rural do litoral viva em condição de vulnerabilidade social muito alta. Estrutura fundiária, tecnologia produtiva, infraestrutura de transportes, organização social da produção, restrições ambientais interagem com as condicionantes naturais, como a produtividade natural das áreas, condicionando a inserção dos agricultores no mercado e em sua condição de auferir renda e garantir sua reprodução. Soma-se a presença ou ausência de políticas públicas que garantam os 
direitos das comunidades rurais, produzindo as situações de vulnerabilidade, processos que devem ser conhecidos para que se interrompam esses ciclos.

\section{Áreas urbanas}

As áreas urbanas do litoral paranaense apresentavam, em 2010, uma população de 240.034 habitantes, sendo 239.097 em 72.650 domicílios particulares permanentes, distribuídos em cerca de $378 \mathrm{~km}^{2}$. Desse total, 5,83\%, ou seja, 13.952 pessoas, moram em áreas com vulnerabilidade social alta $(1,82 \%)$, muito alta $(3,45 \%)$ ou altíssima (0,56\%) (Tabela 10). Nessas áreas, mais de $40 \%$ dos domicílios auferiam renda domiciliar per capita de menos de $1 / 2$ salário mínimo. Nos setores com vulnerabilidade social alta, a renda domiciliar per capita era de $\mathrm{R} \$ 341,75$ e cerca de $18 \%$ da população auferia renda domiciliar per capita de até 1/4 de salário mínimo. Nos de vulnerabilidade muito alta, a RDPC era de R $\$ 284,12$ e o percentual de pessoas que possuíam renda até 1/4 de salário mínimo era de cerca de $17 \%$. Nos setores que apresentaram vulnerabilidade altíssima a RDPC era de $\mathrm{R} \$ 301,35$ e o total de pessoas com renda de até 1/4 de SM era ligeiramente inferior aos dois estratos anteriores, cerca de 13\%. Vale lembrar que apenas setores de condição socioeconômica baixa, com famílias jovens e vivendo em aglomerados subnormais se enquadram na categoria de altíssima vulnerabilidade. Apenas o município de Paranaguá possui áreas classificadas como subnormais, em um total de 16 setores. Contudo, apenas 2 reuniram as condições para serem classificados como de altíssima vulnerabilidade social. Essas áreas devem ser melhor analisadas para se compreender seu padrão de ocupação.

Por outro lado, tem-se 32,5\% da população residindo em áreas de vulnerabilidade social muito baixa, com renda domiciliar per capita de $\mathrm{R} \$ 1.014,43$, menos de $10 \%$ da população do setor com RDPC de até $1 / 2$ SM e menos de $2 \%$ de até $1 / 4$ de SM. Outros $25,5 \%$ da população viviam em setores de vulnerabilidade baixa. Nesses setores, a renda é consideravelmente inferior ao extrato anterior, com $\mathrm{R} \$ 559,32$ e 22,45\% dos domicílios com RDPC de até 1⁄2 SM.

A faixa que agrupou o maior percentual de população - 36\%, sendo $34 \%$ dos domicílios, foi a vulnerabilidade social média. Nesse grupo, a RDPC foi de R $\$ 442,15$ e o percentual da população com RDPC de até $1 / 2$ SM foi de $29 \%$.

Observando a distribuição municipal, a pior situação é a de Guaraqueçaba, seguida por Antonina. Em Guaraqueçaba, município predominantemente rural, 29,25\% dos habitantes das áreas urbanas estão em setores que apresentaram vulnerabilidade muito alta e 29,85\% em setores que apresentaram vulnerabilidade alta (Tabela 11). São apenas 4 setores censitários urbanos, e destes apenas o que corresponde a área central do município possui baixa vulnerabilidade. A área que se 
situa no núcleo urbano do Distrito de Serra Negra apresentou vulnerabilidade média. O isolamento do município e seu caráter eminentemente rural certamente contribuem para essa situação, além das restrições ambientais, tendo em consideração a série de unidades de conservação de uso sustentável e de proteção integral que existem na localidade (KASSEBOEHMER, 2007).

TABELA 10 - SÍNTESE DAS VARIÁVEIS DO IVS POR CATEGORIA DO IVS - SETORES URBANOS

\begin{tabular}{lcccccccccccc}
\hline & DPP & RDPP & V1 & V2 & V3 & V4 & V5 & V6 & V7 & V8 & V9 \\
\hline $\begin{array}{l}\text { Muito } \\
\text { baixa }\end{array}$ & 25.617 & 77.727 & 98,09 & 11,73 & 48,51 & 7,38 & 11,79 & 1014,43 & 1308,50 & 9,37 & 1,83 \\
\hline & 35,26 & 32,51 & & & & & & & & & \\
\hline Baixa & 18.488 & 61.123 & 94,31 & 10,14 & 48,74 & 8,45 & 8,26 & 559,32 & 756,28 & 22,45 & 5,72 \\
\hline & 25,45 & 25,56 & & & & & & & & & \\
\hline Média & 24.704 & 86.295 & 94,05 & 17,95 & 43,76 & 10,74 & 18,07 & 442,15 & 568,64 & 28,99 & 8,08 \\
\hline \multicolumn{1}{c}{} & 34,00 & 36,09 & & & & & & & & & \\
\hline Alta & 1.271 & 4.363 & 84,44 & 10,65 & 48,99 & 9,71 & 7,91 & 341,76 & 579,63 & 42,56 & 17,83 \\
\hline \multicolumn{1}{c}{} & 1,75 & 1,82 & & & & & & & & & \\
\hline Muito alta & 2.223 & 8.254 & 86,81 & 22,74 & 41,98 & 12,85 & 23,57 & 284,12 & 364,39 & 46,61 & 17,34 \\
\hline & 3,06 & 3,45 & & & & & & & & & \\
\hline Altíssima & 347 & 1.335 & 94,51 & 17,13 & 43,15 & 11,49 & 19,25 & 301,35 & 523,51 & 46,30 & 12,98 \\
\hline & 0,48 & 0,56 & & & & & & & & & \\
\hline Total & $\mathbf{7 2 . 6 5 0}$ & $\mathbf{2 3 9 . 0 9 7}$ & & & & & & & & & \\
\hline & $\mathbf{1 0 0 , 0 0}$ & $\mathbf{1 0 0 , 0 0}$ & & & & & & & & & \\
\hline
\end{tabular}

FONTE: Elaborado pela autora a partir dos dados do IBGE (2010).

NOTA: DPP - domicílios particulares permanentes. RDPP - Residentes em domicílios particulares permanentes.

TABELA 11 - RESULTADOS DO IVS POR MUNICÍPIO - SETORES URBANOS

\begin{tabular}{|c|c|c|c|c|c|c|c|c|c|c|c|c|c|c|c|}
\hline \multirow{4}{*}{ Muito baixa } & \multirow[b]{2}{*}{$\mathrm{N}$ setores } & \multicolumn{2}{|c|}{ Antonina } & \multicolumn{2}{|c|}{ Guaraqueçaba } & \multicolumn{2}{|c|}{ Guaratuba } & \multicolumn{2}{|c|}{ Matinhos } & \multicolumn{2}{|c|}{ Morretes } & \multicolumn{2}{|c|}{ Paranaguá } & \multicolumn{2}{|c|}{$\begin{array}{c}\text { Pontal do } \\
\text { Paraná } \\
\end{array}$} \\
\hline & & 3 & 13,64 & & & 33 & 53,23 & 36 & 63,16 & 3 & 25 & 81 & 39,71 & 19 & 44,19 \\
\hline & DPP & 777 & 15,72 & & & 3772 & 41,55 & 4760 & 49,16 & 521 & 24,1 & 13751 & 35,29 & 2036 & 28,97 \\
\hline & RDPP & 2247 & 14,06 & & & 10857 & 37,97 & 13649 & 46,93 & 1616 & 22,65 & 43734 & 32,41 & 5624 & 27,19 \\
\hline \multirow{3}{*}{ Baixa } & $\mathrm{N}$ setores & 10 & 45,45 & 1 & 25 & 16 & 25,81 & 12 & 21,05 & 7 & 58,33 & 44 & 21,57 & 13 & 30,23 \\
\hline & DPP & 2332 & 47,17 & 297 & 37,45 & 2325 & 25,61 & 2341 & 24,18 & 1334 & 61,7 & 7527 & 19,32 & 2332 & 33,18 \\
\hline & RDPP & 7339 & 45,91 & 965 & 36,14 & 7317 & 25,59 & 7252 & 24,94 & 4377 & 61,35 & 26927 & 19,95 & 6946 & 33,59 \\
\hline \multirow{3}{*}{ Média } & $\mathrm{N}$ setores & 2 & 9,09 & 1 & 25 & 12 & 19,35 & 9 & 15,79 & 2 & 16,67 & 70 & 34,31 & 10 & 23,26 \\
\hline & DPP & 484 & 9,79 & 38 & 4,79 & 2769 & 30,5 & 2581 & 26,66 & 307 & 14,2 & 15905 & 40,82 & 2620 & 37,28 \\
\hline & RDPP & 1701 & 10,64 & 127 & 4,76 & 9662 & 33,79 & 8182 & 28,13 & 1141 & 15,99 & 57506 & 42,61 & 7976 & 38,57 \\
\hline \multirow{3}{*}{ Alta } & $\mathrm{N}$ setores & 5 & 22,73 & 1 & 25 & & & & & & & & & 1 & 2,33 \\
\hline & DPP & 1003 & 20,29 & 228 & 28,75 & & & & & & & & & 40 & 0,57 \\
\hline & RDPP & 3431 & 21,46 & 797 & 29,85 & & & & & & & & & 135 & 0,65 \\
\hline \multirow{3}{*}{ Muito alta } & $\mathrm{N}$ setores & 2 & 9,09 & 1 & 25 & 1 & 1,61 & & & & & 7 & 3,43 & & \\
\hline & DPP & 348 & 7,04 & 230 & 29 & 212 & 2,34 & & & & & 1433 & 3,68 & & \\
\hline & RDPP & 1268 & 7,93 & 781 & 29,25 & 755 & 2,64 & & & & & 5450 & 4,04 & & \\
\hline
\end{tabular}




\begin{tabular}{|c|c|c|c|c|c|c|c|c|c|c|c|c|c|c|c|}
\hline \multirow{3}{*}{ Altíssima } & \multicolumn{11}{|l|}{$\mathrm{N}$ setores } & 2 & \multicolumn{3}{|l|}{0,98} \\
\hline & DPP & & & & & & & & & & & 347 & 0,89 & & \\
\hline & RDPP & & & & & & & & & & & 1335 & 0,99 & & \\
\hline \multirow{3}{*}{ Total } & $\mathrm{N}$ setores & 22 & 100 & 4 & 100 & 62 & 100 & 57 & 100 & 12 & 100 & 204 & 100 & 43 & 100 \\
\hline & DPP & 4944 & 100 & 793 & 100 & 9078 & 100 & 9682 & 100 & 2162 & 100 & 38963 & 100 & 7028 & 100 \\
\hline & RDPP & 15986 & 100 & 2670 & 100 & 28591 & 100 & 29083 & 100 & 7134 & 100 & 134952 & 100 & 20681 & 100 \\
\hline
\end{tabular}

FONTE: Elaborado pela autora a partir dos dados do IBGE(2010).

Antonina, por sua vez, tem 7,04\% dos moradores de suas áreas urbanas residindo em setores de vulnerabilidade muito alta e 21,46\% em setores de vulnerabilidade alta. A situação de Antonina, de certa estagnação econômica, que se reflete nos altos índices de vulnerabilidade, bem como nas taxas negativas de crescimento populacional apresentadas na última década $(-1,5 \%$ no período 2000-2010, segundo dados do IBGE, 2010), deve-se em parte ao declínio de sua importância como polo portuário, com a desativação do Terminal Barão de Teffé, em 2006, e a permanência de operação apenas do Terminal da Ponta do Félix. Por outro lado, Antonina não se beneficiou do desenvolvimento da atividade turística como observado em Morretes, uma vez que o acesso ferroviário até o município está desativado desde 1976 (APPA, 2012). Os setores em pior situação encontram-se às margens da rodovia PR-408, no entorno do terminal Pontal do Félix e na área localizada mais ao fundo da Baía de Antonina, na área conhecida como Portinho de Cima, com as melhores áreas na região central do município. Também o núcleo urbano do distrito de Cachoeira de Cima apresentou vulnerabilidade muito alta.

Morretes não possui nenhum setor com vulnerabilidades alta ou muito alta, e a maior parte de sua população urbana, 61,35\%, vive em setores de baixa vulnerabilidade. Dois setores apresentaram média vulnerabilidade, abrangendo cerca de $16 \%$ da população urbana, uma no núcleo urbano do distrito de Porto de Cima e outro no bairro Vila dos Ferroviários.

Entre os municípios caracterizados pelo uso balneário, Pontal do Paraná e Matinhos apresentam situação melhor. Em Pontal do Paraná, mais da metade da população vive em setores de baixa e muito baixa vulnerabilidade social. Cerca de $38 \%$ vivem em áreas de média vulnerabilidade social e pouco mais de $0,5 \%$ em um setor de alta vulnerabilidade, na área que corresponde a comunidade pesqueira do Maciel. Destaca-se um padrão de ocupação do espaço caracterizado pela segregação espacial desses setores, uma vez que a rodovia PR-412 corta os municípios de Pontal e Matinhos. Isso tem determinado uma divisão entre os setores que são predominantemente utilizados para o uso de veraneio, situados em direção à beira-mar, e no qual a população residente possui melhor situação socioeconômica, e aqueles situados na margem oposta da rodovia, nos quais vivem 
a população local de menor condição socioeconômica e com menor acesso aos serviços públicos de saneamento, como apontado por Polidoro e Deschamps (2013). O padrão pode ser observado claramente no mapa (Figura 02), bem como na Tabela 12.

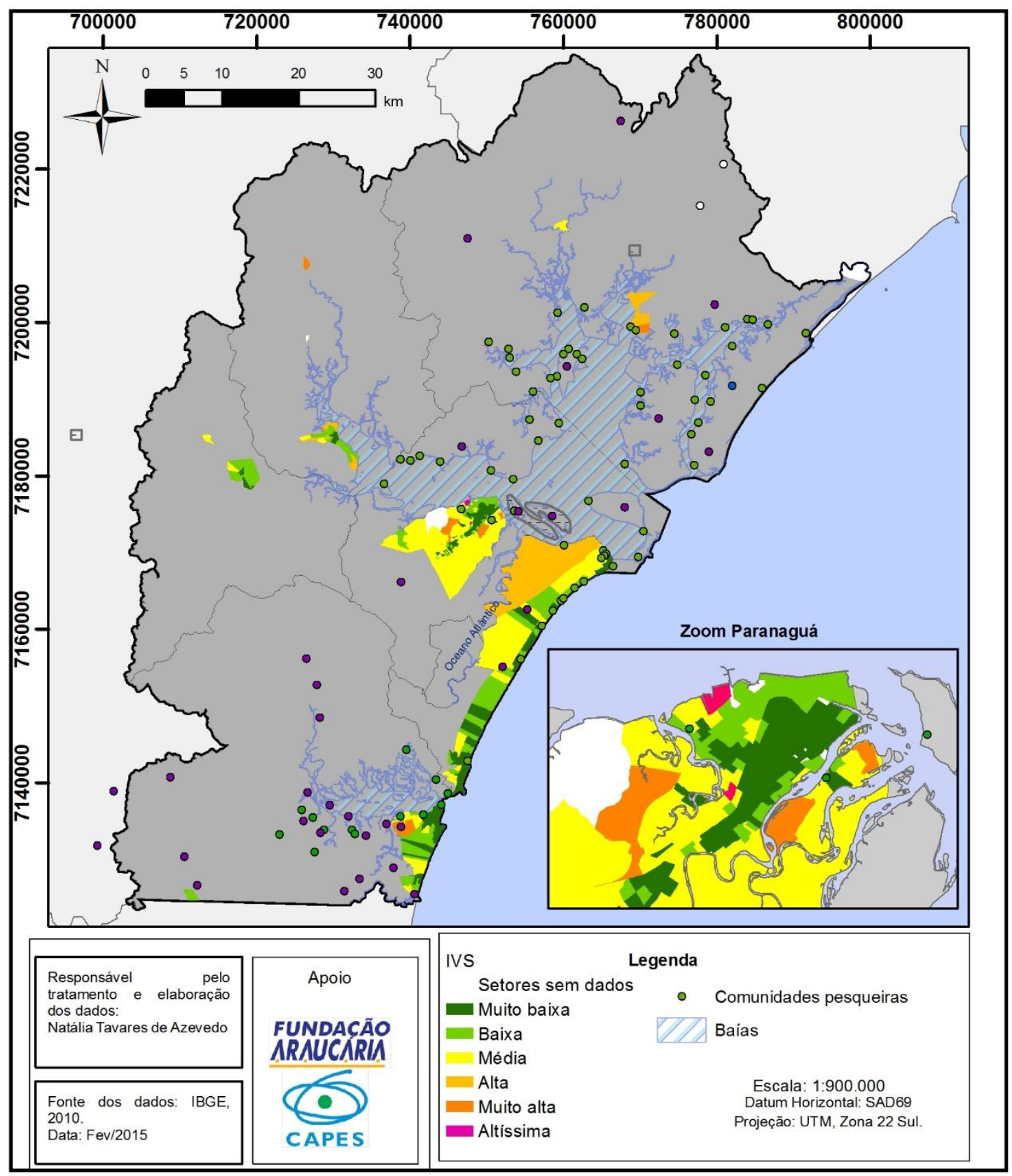

FIGURA 02 - ÍNDICE DE VULNERABILIDADE SOCIAL NOS SETORES URBANOS 
TABELA 12 - QUANTIDADE E PERCENTUAL DE DOMICÍLIOS DE USO OCASIONAL - SETORES URBANOS

\begin{tabular}{llcccc}
\hline & & Muito baixa & Baixa & Média & Alta \\
\cline { 2 - 6 } Guaratuba & DPP & 8.646 & 3.026 & 1.353 & 133 \\
\hline & DUO & 7.866 & 2.666 & 958 & 70 \\
\hline Matinhos & DPP & 14.295 & 6.280 & 2.727 & - \\
\hline & DUO & 13.340 & 5.801 & 2.244 & - \\
\hline & $\%$ & 93,32 & 92,37 & 82,29 & - \\
\hline Pontal & DPP & 7.989 & 7.972 & 4.136 & - \\
\hline & DUO & 7.036 & 7.249 & 3.373 & - \\
\hline
\end{tabular}

FONTE: Elaborado pela autora a partir dos dados do IBGE (2010).

Em Pontal do Paraná, isso corresponde a áreas da localidade de Mangue Seco, na região de Pontal do Sul, e nas áreas na margem oposta da rodovia em balneários como Shangrilá, Ipanema, Primavera, Canoas, Santa Terezinha, Praia de Leste, além de áreas próximas ao aterro sanitário.

Em Matinhos, cerca de $46 \%$ dos residentes da área urbana vivem em áreas de muito baixa vulnerabilidade social e cerca de $25 \%$ em áreas de baixa vulnerabilidade. Os outros $28 \%$ vivem em áreas que, no conjunto do litoral, foram classificadas como de média vulnerabilidade, mas são as áreas que apresentam os piores índices do município. São áreas que ficam contíguas ao balneário de Caiobá, nas localidades de Tabuleiro I e II e Vila Nova, assim como a localidade de Rio da Onça e as áreas dos balneários nas margens opostas à beira-mar da PR-412, como Gaivotas, Praia Grande, Betaras e Albatroz.

Em Guaratuba, cerca de $36 \%$ da população urbana vive em setores de vulnerabilidade social muito baixa, 25,6\% em áreas de baixa vulnerabilidade. Nas áreas de média vulnerabilidade, vivem $33,7 \%$ e 2,56\% em áreas de vulnerabilidade muito alta. Esta corresponde à localidade de Mirim, área situada aos fundos da pista de pouso (aeroporto) de Guaratuba e que possui divisa com o rio de mesmo nome. Já os setores de vulnerabilidade média estão em parte de áreas dos bairros Piçarras (onde existe uma comunidade pesqueira), Carvoeiro, Cohapar e Vila Esperança, todas áreas mais distantes da orla. Além disso, há setores em pior situação, assim como nos outros dois municípios praianos, nas áreas da PR-412 na margem oposta à beira mar, especialmente nos balneários Nereidas e Coroados, neste último com destaque para as áreas já próximas à barra do Rio Saí.

Como destacaram Deschamps e Kleinke (2000), bem como Esteves (2011), essas são áreas de ocupação mais recente no litoral, resultado de fluxos migratórios que tiveram seu auge na década de 1990, mas que seguem ocorrendo. Em que pese essas não serem áreas que se encontram nos 
maiores índices de vulnerabilidade social se considerada a totalidade do litoral, são as áreas de pior situação socioeconômica nesses municípios e implicam num padrão claro de segregação socioespacial presente nos municípios de uso praiano e que, à luz dos dados migratórios levantados por outros pesquisadores, como Deschamps e Kleinke (2000) e Esteves (2011), demonstram claramente uma tendência de migração de população de renda mais baixa, que ocupa áreas mais isoladas e com piores condições de infraestrutura. Enquanto isso, as áreas dotadas de infraestrutura possuem, em grande parte, imóveis de uso ocasional que ficam fechados durante todo o ano, só sendo utilizados na temporada.

Por fim, temos a cidade polo do litoral, Paranaguá, onde cerca de $32 \%$ dos residentes urbanos vivem em área de vulnerabilidade social muito baixa, que correspondem principalmente às áreas do eixo mais central da cidade, entre a BR-277 (Avenida Ayrton Senna) e o Centro Histórico, como João Gualberto, Leblon, Bockman, Campo Grande, Tuiuti, Costeira, Oceânica. Depois, cerca de $20 \%$ reside em áreas de baixa vulnerabilidade, que inclui bairros entre o Porto de Paranaguá e a área central, bairros que margeiam o Rio Itiberê, como Vila São Vicente, Estradinha, Vila Itiberê, Ponta do Caju. Nas áreas de vulnerabilidade média residem cerca de 19\% da população urbana. Territorialmente, configuram grande parte do espaço urbano do município de Paranaguá. São áreas que se situam entre a BR-277 e a via alternativa para a área portuária, Avenida Senador Atílio Fontana, como os Jardins Figueira e Iguaçu, Parque São João, Emboguaçu, Jardim Araçá, além de áreas como o Rocio e a Vila Guarani. Além disso, grande parte dos setores situados ao longo da PR-407, que dá acesso a Pontal do Paraná, como Jardim Paranaguá, Jardim Esperança, Vila Garcia, Jardim Ouro Fino, Porto Seguro e Jardim Paraná, áreas de ocupação mais recente e que seguem em crescimento.

Ainda, tem-se cerca de $4 \%$ da população parnanguara vivendo em áreas de vulnerabilidade social muito alta. Trata-se de áreas às margens da BR-277 e da via alternativa de acesso ao porto, como o Imbocuí, Vila São João e parte do Parque São João. Além disso, há setores localizados na Ilha de Valadares, especialmente em suas duas extremidades, que também apresentam vulnerabilidade social muito alta. Por fim, há os dois setores de altíssima vulnerabilidade, que correspondem a 1\% da população urbana de Paranaguá, um localizado na área próxima do Terminal da Fospar e do Terminal da Catalini (granéis líquidos, onde explodiu o navio Vicuña em 2004), na Vila Portuária, e outro localizado na localidade do Emboguaçu, próxima ao manguezal, onde já ocorreu um incêndio que causou derramamento de produtos químicos nos galpões da empresa Brasmar, que fica em área contígua. 
Godoy (2000) analisou a relação entre a constituição urbana de Paranaguá, a distribuição espacial da população e a reestruturação produtiva da atividade portuária, que implicou em mudanças tecnológicas, diminuição da demanda de mão de obra e especialização em funções de maior grau hierárquico. Destaca, ainda, em termos espaciais, a expansão da zona portuária, que passa a estar cada vez mais espalhada no eixo de acesso à zona portuária. Segundo a autora, o segmento mais especializado ligado à atividade portuária direta e indiretamente ocupa as localizações mais privilegiadas no espaço urbano, enquanto os trabalhadores semi ou não especializados ligados às atividades portuárias direta e indiretamente ocupam áreas mais periféricas. Porém, a situação pior fica por conta da informalidade e precarização do mercado de trabalho, tendo em vista o declínio da ocupação de mão de obra no setor portuário em decorrência do avanço tecnológico. Segundo Godoy, são as populações periféricas não ligadas à atividade portuária as que se encontram em pior situação. Os dados do IVS parecem corroborar para a continuidade desses processos em termos espaciais, que merecem maior investigação.

\section{Algumas considerações a título de finalização}

O objetivo deste artigo foi estabelecer as bases e apresentar a construção e alguns resultados, bem como possíveis caminhos, para a análise da distribuição espacial da vulnerabilidade social no litoral paranaense. Obviamente, dada a abrangência espacial do estudo, não é possível analisar detalhadamente o processo de diferenciação socioespacial no litoral no espaço de um artigo. Porém, é possível fazer algumas inferências. Pode-se apontar, retomando-se as reflexões teóricas que embasam a pesquisa, que os processos econômicos que ocorrem nas áreas urbanas e rurais nos municípios costeiros do Paraná têm implicações no processo de diferenciação socioespacial.

Nas áreas rurais, observou-se que uma parte significativa da população vive em áreas de vulnerabilidade social muito alta. Isso é resultado de um processo histórico de longa data, que fez com que, não apenas no Paraná, as áreas rurais costeiras fossem perdendo significância em relação à produção agrícola, em face da expansão do agronegócio e de formas mais modernizadas de agricultura no interior do país. Observou-se que a inserção de uma agricultura mais tecnificada e a inserção de atividades de turismo e lazer parecem ter relação com as transformações socioespaciais e a vulnerabilidade. Guaraqueçaba se sobressai nesse cenário, pois quase a totalidade de suas áreas rurais tem vulnerabilidade social muito alta. Parece se destacar o fato de a região ter se tornado um “território-reserva" (HAESBAERT; LIMONAD, 2007), o que, por um lado, pode ter freado os 
processos de pressão sobre o meio ambiente decorrentes do modelo adotado para o desenvolvimento no período do regime militar (com os incentivos fiscais as atividades agrícolas e agroflorestais) (MIGUEL, 1997), por outro lado tem limitado francamente a busca de alternativas para a sobrevivência da população local.

Ao se considerar as áreas urbanas, vê-se a reprodução, ainda que em menor escala, do processo de segregação espacial que conforma o mundo urbano capitalista. Nos municípios praianoturísticos, isso se expressa na divisão territorial das áreas das segundas residências de veranistas e das áreas destinadas à população local. Em Paranaguá, essa configuração é mais complexa, mas se destaca a relação entre o eixo da zona portuária, com suas duas vias de acesso, e o local de moradia de pessoas com alta vulnerabilidade social.

Este artigo, ao cotejar as formas de segregação socioespacial presentes no litoral atualmente, espera ser um estímulo a estudos que busquem relacionar as particularidades municipais e locais com os processos mais abrangentes que condicionam o desenvolvimento da região. Ou seja, é uma provocação a que se pense o litoral do Paraná com uma unidade, e que os estudos de caso, que já se tornam abundantes e que são necessários, busquem dialogar com os processos mais abrangentes, fomentando reflexões que tornem possível pautar políticas de maior envergadura para o desenvolvimento da região. Não qualquer desenvolvimento, mas um que nos leve à superação da pobreza e da desigualdade que lamentavelmente marcam o cenário socioeconômico de uma região de abundante riqueza natural.

\section{Referências}

ACSELRAD, H. O conhecimento do ambiente e o ambiente do conhecimento: anotações sobre a conjuntura do debate sobre vulnerabilidade. Em pauta, Rio de Janeiro, n. 32, v. 11, p. 115-129, 2013.

ACSELRAD, H. Vulnerabilidade social, conflitos ambientais e questão urbana. O Social em Questão, Rio de Janeiro, n. 33, ano XVIII, p. 57-68, 2015.

ACSELRAD, H; MELlO, C. C. A.; BEZERRA, G. N. O que é justiça ambiental? Rio de Janeiro: Garamond, 2009.

ADMINISTRAÇÃO DOS PORTOS DE PARANAGUÁ E ANTONINA (APPA). Plano de Desenvolvimento e Zoneamento do Porto Organizado de Antonina - PDZPO. Florianópolis, 2012. 
ALVES, H. P. Metodologias de integração de dados sociodemográficos e ambientais para análise de vulnerabilidade socioambiental em áreas urbanas no contexto das mudanças climáticas. In: HOGAN, D. J.; MARANDOLA, E. (Orgs.). População e mudança climática. Dimensões humanas das mudanças ambientais globais. Campinas: Nepo/Unicamp; Brasília: Unfpa, 2006.

ANDERBERG, Michael R. Cluster analysis for aplications. New York: Academic Press, 1973.

ANDRIGUETTO-FILHO, J. M. Sistemas técnicos de pesca e suas dinâmicas de transformação no litoral do Paraná, Brasil. 1999. Tese (Doutorado em Meio Ambiente e Desenvolvimento) Universidade Federal do Paraná, Curitiba.

BÉNÉ, C. When fishery rhymes with poverty, a first step beyond the old paradigm on poverty in small-scale fisheries. World Development, n. 31, v. 6, p. 949-975, 2003.

BÉNÉ, C. Are fishers poor or vulnerable? Assessing economic vulnerability in small-scale fishing communities. Journal of Development Studies, v. 45, n. 6, p. 911-933, 2009.

BIASSIO, Ade. Agrobiodiversidade em escala familiar nos municípios de Antonina e Morretes (PR): base para sustentabilidade socioeconômica e ambiental. 2011. Dissertação (Mestrado em Engenharia Florestal) - Universidade Federal do Paraná, Setor de Ciências Agrárias.

BORSATTO, R. S.; OTTMAN, M. M. A.; FONTE, N. N.; CIDADE JÚNIOR, H. A.; ALANO, E. R. C.; CAVALLET, V. J. Problemas agrários do litoral paranaense: abordagem histórica. Scientia Agraria, Curitiba, v. 8, n. 4, p. 421-430, 2007.

BRANDÃO, C. Território e desenvolvimento: as múltiplas escalas entre o local e o global. 2. ed. Campinas: Editora da Unicamp, 2012.

BRANDENBURG, A.; FERREIRA, A. D. D.; SANTOS, L. J. C. Dimensões socioambientais do rural contemporâneo. Desenvolvimento e Meio Ambiente, Curitiba, n. 10, p. 119-129, 2004.

CARLOS, A. F. A. Diferenciação socioespacial. Cidades, São Paulo, v. 4, n. 6, p. 45-60, 2007.

CAVALLET, L. E.; RIBEIRO, H. I.; MARTINS, C. B. Cooperação técnica para certificação de agricultura orgânica na região litorânea do Paraná. Rev. Acad., Ciênc. Agrár. Ambient., Curitiba, v. 11, Supl. 2, p. S169-S174, 2013.

CUTTER, S. L. A ciência da vulnerabilidade: modelos, métodos e indicadores. Revista Crítica de Ciências Sociais, Coimbra, n. 93, p. 59-69, jun. 2011.

DENARDIN, V. F. Sustentabilidade de alternativa de produção desenvolvida por agricultores familiares em unidades de conservação no Litoral do Paraná. Guaju - Revista Brasileira de Desenvolvimento Territorial Sustentável, v. 1, n. 1, 2015.

DESCHAMPS, M. V.; KLEINKE, M. L. U. Os fluxos migratórios e as mudanças socioespaciais na ocupação contínua litorânea do Paraná. Revista Paranaense de Desenvolvimento, Curitiba, n. 99, p. 45-59, jul./dez. 2000. 
ESTEVES, C. J. O. Vulnerabilidade socioambiental na área de ocupação contínua do litoral do Paraná - Brasil. 2011. Tese (Doutorado em Geografia) - Universidade Federal do Paraná, Programa de Pós-Graduação em Geografia, Curitiba.

FERREIRA, M. R.; NEGRELLE, R. R. B.; ZANATTA, R. A. F. Terra inválida, gente invisível: o caso das comunidades rurais extrativistas do litoral paranaense. In: DENARDIN, V. F.; ABRAHÃO, C. M. S.; QUADROS, D. A. Litoral do Paraná: reflexões e interações. Matinhos: Editora UFPR Litoral, 2011.

FUNDAÇÃO SISTEMA ESTADUAL SISTEMA DE ANÁLISE DE DADOS (SEADE). Índice paulista de vulnerabilidade social. São Paulo, 2013.

GÓES, L. M. Conservação e grandes empreendimentos de infraestrutura no litoral do Paraná: a ferrovia Lapa-Paranaguá. 2014. Dissertação (Mestrado em Meio Ambiente e Desenvolvimento) Universidade Federal do Paraná, Curitiba.

GODOY, A. Reestruturação produtiva e polarização do mercado de trabalho em Paranaguá - PR. Revista paranaense de desenvolvimento, Curitiba, n. 99, p. 5-25, jul./dez. 2000.

GOMES, C. M. P.; FlORIT, L. F.; ABRAHÃO, C. S.; SAMPAIO, C. A. C. Agriculturas e naturezas no território rural: o caso da microbacia do Rio Sagrado em Morretes (PR). Guaju, Matinhos, v. 1, n. 1, p. 44-63, jan./jun. 2015.

HAESBAERT, R. Região, diversidade territorial e globalização. GEOgraphia, Niterói, n. 1, v. 1, 1999.

HARVEY, D. A produção capitalista do espaço. São Paulo: Annablume, 2005.

IGNÁCIO, S. A. Tipologia dos municípios paranaenses segundo indicadores socioeconômicos e sociodemográficos - Uma análise estatística. Curitiba: PUCPR, 2002.

INSTITUO DE PESQUISA ECONÔMICA APLICADA (IPEA). Atlas da vulnerabilidade social nos municípios brasileiros. Brasília, 2015. Disponível em: <http://ivs.ipea.gov.br/ivs/data/rawData/publicacao_atlas_ivs.pdf, Acesso em 12/12/2015,

KAMINSKI, T. O trabalho agroflorestal: apropriação e atividade coletiva no Grupo Gralha Azul, município de Morretes - PR. 2014. Dissertação (Mestrado em Meio Ambiente e Desenvolvimento) - Universidade Federal do Paraná, Curitiba.

KASSBOEHMER, A. L. Restrições e impactos da legislação ambiental aplicada no município de Guaraqueçaba - Paraná. 2007. Dissertação (Mestrado em Engenharia Florestal) Universidade Federal do Paraná, Curitiba.

KATZMAN R. Notas sobre la medición de la vulnerabilidad social. Documentos de Trabajo de IPES/Colección Aportes Conceptuales No. 2. Montevideo: Universidad Católica del Uruguay, 2002.

KAZTMAN, R. Activos y estructura de oportunidades. Estudios sobre las raíces de la vulnerabilidad social en Uruguay. Uruguay: Pnud - Uruguay e Cepal - Oficina de Montevideo, 1999. 
LEFEBVRE, H. Lógica formal, lógica dialética. Rio de Janeiro: Civilização Brasileira, 1991.

MARCHIORO, N. P. X. Mudança técnica e sustentabilidade dos sistemas agrários: o caso de Morretes. In: NEGRELLE, R. R. B.; LIMA, R. E. Meio ambiente e desenvolvimento no litoral do Paraná: subsídios à ação. Curitiba: Nimad - UFPR, 2002a.

MARCHIORO, N. P. X. Sistemas técnicos de produção agrícola: o caso do município de Morretes. In: RAYNAUT, C.; ZANONI, M.; LANA, P. C.; FLORIANI, D.; FERREIRA, A. D. D.; ANDRIGUETTO FILHO, A. Desenvolvimento e meio ambiente: em busca da interdisciplinaridade - pesquisas urbanas e rurais. Curitiba: Editora da UFPR, 2002b.

MINGOTI, S. A. Análise de dados através de métodos de estatística multivariada: uma abordagem aplicada. Belo Horizonte: Editora UFMG, 2005.

NAZARENO, L. R.; SOUZA JUNIOR, P. C; IGNÁCIO, S. A. Índice de Vulnerabilidade das Famílias Paranaenses: Mensuração a partir do Cadastro Único para Programas Sociais CadÚnico. Nota Técnica Ipardes. Curitiba, 2012. Disponível em: <http://www.desenvolvimentosocial.pr.gov.br/arquivos/File/familia_paranaense/Indice_Vulnerabili dade_familias.pdf>. Acesso em:10 de novembro de 2015.

OLIVEIRA, E. A. Contexto político, viabilização de grandes obras e prováveis impactos ambientais no litoral e Serra do Mar do Paraná. Observatório da Conservação Costeira - $\mathbf{O C}_{2}, 2013$. Disponível em: <http://www.observatoriocosteiro.org/news/contexto-politico\%2cviabiliza\%C3\% A7\% C3\%A3o-de-grandes-obras-e-provaveis-impa'ctos-ambientais-no-litoral-eserra-do-mar-do-parana/>. Acesso em: 03 de janeiro de 2016.

PIERRI, N. O litoral do Paraná: entre a riqueza natural e a pobreza social. Desenvolvimento e Meio Ambiente, Curitiba, n. 8, p. 25-41, 2003.

PIERRI, N. P.; ANGULO, R. J.; SOUZA, M. C.; KIM, M. K. A ocupação do solo no litoral paranaense: condicionantes, conflitos e tendências. Desenvolvimento e Meio Ambiente, Curitiba, n. 13, p. 137-167, 2006.

PREFEITURA MUNICIPAL DE BELO HORIZONTE (PMBH). Secretaria Municipal de Planejamento, Orçamento e Informação. Secretaria Municipal Adjunta de Planejamento. Série histórica IQVU 1994-2000-2006: notas metodológicas. Belo Horizonte, 2008.

GONZALES, L. (Org.). Lecturas sobre vulnerabilidad y desigualdad social. Córdoba: Universidad de Córdoba, 2009.

POLIDORO, M.; DESCHAMPS, M. V. Segundas residências e urbanização no litoral do Paraná. Revista Paranaense de Desenvolvimento, Curitiba, n. 34, p. 213-235, 2013.

RENCHER, A. C. Methods of Multivariate Analysis. New York: Wiley-Interscience, 2002.

RODRIGUES, A.; TOMMASINO, H.; FOLADORI, G.; GREGORCZUK, A. É correto pensar a sustentabilidade em nível local? Uma análise metodológica de um estudo de caso em uma Área de 
Proteção Ambiental no litoral sul do Brasil. Ambiente e sociedade, Campinas, v. 5, n. 2, p. 109127, 2003.

ROLNIK, R. Exclusão territorial e violência. São Paulo em Perspectiva, São Paulo, v. 13, n. 4, p. 100-111, 1999.

SALMON, L. P. G.; KAMINSKI, T. C. G.; LESAMA, M. F.; SEOANE, C. E.; SILVA, J. A. A formação de um coletivo de trabalho agroflorestal: o caso do grupo Gralha Azul, em Morretes - PR. Cadernos de Agroecologia, Recife, v. 8, n. 2, 2013.

SAMPAIO, C. A. C.; ZAMIGNAN, G. Estudo da demanda turística: experiência de turismo comunitário da microbacia do Rio Sagrado, Morretes (PR). Cultur, Ilhéus, ano 6, n. 1, p. 25-39, fev. 2012.

SAMPAIO, C. P. Estratégias de reprodução da agricultura familiar na área de proteção ambiental de Guaraqueçaba - litoral norte do Paraná. 2004. Tese (Doutorado em Engenharia Agrícola) - Universidade Estadual de Campinas, Faculdade de Engenharia Agrícola, Campinas.

SANTOS, J. C.; VELOSO, V. B.; MATEUS, B. O.; FURQUIM, T. W.; BERNARDI, W. K.; SOUZA, T. A. Redes de comercialização: consolidando vínculos entre agricultores(as) e consumidores(as) de produtos agroecológicos no litoral do Paraná. Mostra de Projetos Nós Podemos Paraná. FIEP, 2013.

SANTOS, M. A natureza do espaço: técnica e tempo, razão e emoção. 4. ed. São Paulo: Edusp, 2006.

SECRETARIA DE AGRICULTURA E ABASTECIMENTO (SEAB). Departamento de Economia Rural (DERAL). Valor bruto da produção agropecuária. Relatório Municipal 2014. Curitiba. 2015.

SECRETARIA DE ESTADO DE PLANEJAMENTO E DESENVOLVIMENTO ECONÔMICO (SEPLAN AMAZONAS). Índice de vulnerabilidade social do Amazonas. Manaus, 2007. Disponível em: <http://www.ivs.am.gov.br/equipetecnica.php>. Acesso em: 05 de junho de 2013.

SEOANE, C. E.; PINKUSS, I. L.; SILVA, J. A.; SALMON, L. P. G.; FROUFE, L. C. M.; LAGO, M. L. Atividades e práticas em coletivos de trabalho - mutirões - em agroflorestas agroecológicas do litoral do Paraná, Brasil. Cadernos de Agroecologia, Recife, v. 8, n. 2, 2013.

SILVA, H. J. H. O desenvolvimento da maricultura no paraná: situação atual e perspectivas. 2014. Dissertação (Mestrado em Meio Ambiente e Desenvolvimento) - Universidade Federal do Paraná.

SOJA, E. W. Geografias pós-modernas: a reafirmação do espaço na teoria social crítica. Rio de Janeiro: Zahar, 1993.

VAN KAICK, T. Análise crítica dos indicadores ambientais oficiais relacionados ao saneamento básico, tendo como estudos de caso quatro comunidades rurais do litoral norte do estado do Paraná - Brasil. 2007. Tese (Doutorado em Meio Ambiente e Desenvolvimento) Universidade Federal do Paraná, Curitiba. 
ZANONI, M., FERREIRA, A. D.; MIGUEL, L. A.; FLORIANI, D.; CANALI, N.; RAYNAUT, C. Preservação da natureza e desenvolvimento rural: dilemas e estratégias dos agricultores familiares em Áreas de Proteção Ambiental. Desenvolvimento e Meio Ambiente, Curitiba, v. 2, p. 39-55, 2000.

Artigo recebido em 09/03/2016. Aceito para publicação em 30/09/2016. 